\title{
Radical Cations of Phenyl-Substituted Aziridines: What are the Conditions for Ring-Opening?
}

\author{
Carsten Gaebert, ${ }^{\mathrm{a}, \dagger}{ }^{\dagger}$ Jochen Mattay, ${ }^{\mathrm{a} *}$ Marion Toubartz, ${ }^{\mathrm{b}}$ Steen \\ Steenken, b Beat Müller, ${ }^{\mathrm{c}}$,
}

\section{Abstract:}

Radical cations were generated from different phenyl-substituted aziridines by pulse radiolysis in aqueous solution containing $\mathrm{TlOH}^{\bullet+}, \mathrm{N}_{3}{ }^{\bullet}$ or $\mathrm{SO}_{4}{ }^{-}$as oxidants or in $n$-butyl chloride, by ${ }^{60} \mathrm{Co}-\gamma$-radiolysis in Freon matrices at $77 \mathrm{~K}$, and in some cases by flash photolysis in aqueous solution. Depending on the substitution pattern of the aziridines, two different types of radical cations are formed: if the $\mathrm{N}$ atom carries a phenyl ring, the aziridine appears to retain its structure after oxidation and the resulting radical cation shows an intense band at 440-480 $\mathrm{nm}$, similar to that of the radical cation of dimethylaniline. Conversely, if the $\mathrm{N}$ atom carries an alkyl substituent while a phenyl ring is attached to a $\mathrm{C}$-atom of the aziridine, oxidation results in spontaeous ring opening to yield azomethine ylide radical cations which have broad absorptions in the 500-800 $\mathrm{nm}$ range. In aqueous solution the two types of radical cations are quenched by $\mathrm{O}_{2}$ with different rates, whereas in $n$-butyl chloride, the ring-closed aziridine radical cations are not quenchable by $\mathrm{O}_{2}$. Quantum chemical calculations results confirm the assignment of these species and allow to rationalize the different effects that phenyl rings have if they are attached in different positions of aziridines.

In the pulse radiolysis experiments in aqueous solution, the primary oxidants can also be observed,whereas in $n$-butyl chloride a transient at $325 \mathrm{~nm}$ remains unidentified. In the Laser Flash experiments, both types of radical cations were also observed.

\footnotetext{
a) Prof. Jochen Mattay, Dr, Carsten Gaebert, Fakultät für Chemie, Universität Bielefeld, D-33501 Bielefeld, Germany.E-mail: mattay@uni-bielefeld.de

$\left.{ }^{b}\right)$ Prof. Steen Steenken, Dr. Marion Toubartz, Max-Planck-Institut für Strahlenchemie, D-45470 Mülheim/Ruhr, Germany.

c) Prof. Thomas Bally, Dr. Beat MüllerDepartement de Chimie, Université de Fribourg, CH-1700 Fribourg, Switzerland.E-mail:Thomas.Bally@unifr.ch

†) Present address : Bundesamt für Umwelt, Wald und Landschaft, 3003 Bern, Switzerland

$\dagger$ ) Present address: Consortium für elektrochemische Industrie GmbH, Zielstattstr. 20, D-81379 München, Germany
} 


\section{Introduction}

Aziridines and their reactions are of great interest due to their synthetic and pharmacological importance. $[1,2]$ On irradiation or on thermal activation aziridines undergo ring opening to the corresponding azomethine ylides which can be trapped in [3+2] cycloadditions with various dipolarophiles, to form nitrogen containing five membered heterocycles. ${ }^{[3-5]}$ Under photoinduced electron transfer (PET) conditions the aziridine is oxidized to the corresponding radical cation, which can react in a similar manner.[6-10] In the course of our investigations aimed at the applications of aziridines in organic synthesis $[10,11]$ we became interested in the reactive intermediates of the $[3+2]$ cycloadditions, i.e. the azomethine ylides and the radical cations of the aziridines, to elucidate the mechanisms of the reactions. A few years ago we published the results of studies in which azomethine ylides were generated by laser flash photolysis. $[12,13]$ In the present study we investigate the radical cations that are obtained on pulse radiolysis or ${ }^{60} \mathrm{Co}-\gamma$-radiolysis of different phenylaziridines.

Reports on radical cations of aziridines are scarce. In 1976 Holmes and Terlouw ${ }^{[14]}$ reported that the metastable peaks and kinetic energy release of $\mathrm{C}_{2} \mathrm{H}_{5} \mathrm{~N}^{+\bullet}$ obtained from dimethylamine, piperidine, or pyrrolidine were indistinguishable from those obtained from aziridine. This led them to propose for the first time that azriridine undergoes ring opening to azomethine ylide radical cation on ionization. Conversely, three years later Maquestiau et. al. reported that $\mathrm{C}_{2} \mathrm{H}_{5} \mathrm{~N}^{+\bullet}$ generated from aziridine and pyrrolidine have distinct collision induced dissociation (CID) spectra, which led them to claim that the aziridine radical cation retains its ring-closed structure.[15] In 1984 Lien and Hopkinson carried out UHF/4-31G calculations which predicted that the ring opening of the arziridine radical cation is exothermic by over $26.5 \mathrm{kcal} / \mathrm{mol} .[16]$

Around the same time Schaap et al. investigated the photooxygenation of various substituted aziridines.[17-19] They explained the observed reaction products in terms of ring-opened intermediates. Finally, in 1986 Qin and Williams measured the ESR-spectra of parent aziridine subjected to $\gamma$-radiolysis in Freon glasses at $77 \mathrm{~K}$. These showed the unmistakable signature of an allylic radical which led these authors to propose that the azridine radical cation undergoes ring-opening, even under cryogenic conditions. [20] 
The substrates examined experimentally in the present study are 1-phenyl aziridine (1), 1butyl-phenylaziridine (2a), the trans-2,3-diphenylaziridines $\mathbf{3 a}$ and $\mathbf{3 b}$, the 1,2-diphenylaziridines $\mathbf{4 a}$ and $\mathbf{4 b}$, and 1,2,3-triphenylaziridine (5). Computational model studies were done on compounds $\mathbf{2} \mathbf{b}$ and $\mathbf{3 c}$, instead of the $n$-butyl derivatives, $\mathbf{2} \mathbf{a}$ and $\mathbf{3 b}$ (see Scheme 1)

Scheme 1 here

\section{Results and Discussion}

\subsection{Pulse Radiolysis and ${ }^{60}$ Co- $\gamma$-irradiation}

N-Phenyl aziridine. The UV-spectrum recorded $0.9 \mu$ s after irradiating an $\mathrm{N}_{2} \mathrm{O}$-saturated solution of $0.1 \mathrm{~mm} 1$-phenyl aziridine (1) containing $1 \mathrm{mM} \mathrm{Tl}_{2} \mathrm{SO}_{4}$ at $\mathrm{pH} 6.6$ with an electron pulse (Figure 1) shows the $360 \mathrm{~nm}$ band of the oxidant, $\mathrm{TlOH}^{\bullet+} .{ }^{[21]}$ This absorption decreases with a rate constant of $k=1.4 \times 10^{9} \mathrm{M}^{-1} \mathrm{~s}^{-1}$, while a new band arises with the same rate constant at $440 \mathrm{~nm}$ (its maximum intensity is reached after $15.3 \mu \mathrm{s}$ ). The presence of an isosbestic point at $420 \mathrm{~nm}$ suggests that the observed transformation occurs in a single step. The $440 \mathrm{~nm}$ transient is quenchable with oxygen $\left(k=5.5 \times 10^{7} \mathrm{M}^{-1} \mathrm{~s}^{-1}\right)$.

Another transient with an absorption peaking near $335 \mathrm{~nm}$ whose maximum is reached $5.3 \mu \mathrm{s}$ after the electron pulse (i.e. about three times more rapidly than that of the $440 \mathrm{~nm}$ transient) is formed. Unfortunately, the absorptions of $\mathrm{TlOH}^{\bullet+}$.prevented a quantitative assessment of the kinetics for the formation and decay of this species which might be an adduct radical of $\mathbf{1}$ and $\mathrm{OH}^{\bullet}$ (cf. below).

\section{Figure 1}

When oxidation is effected by $\mathrm{SO}_{4}{ }^{--}$(Figure 2) the $440 \mathrm{~nm}$ transient arises with a rate constant of $9.2 \times 10^{9} \mathrm{M}^{-1} \mathrm{~s}^{-1}$. Its quenching with oxygen occurs with a rate constant $\left(k=6.0 \times 10^{7}\right.$ $\mathrm{M}^{-1} \mathrm{~s}^{-1}$ ) in good agreement with the one found after oxidation of 1 with $\mathrm{TlOH}^{\bullet+}$. Pulse radiolysis of $4 \mathrm{mM}$ of aziridine $\mathbf{1}$ in $n$-butyl chloride, and ${ }^{60} \mathrm{Co}-\gamma$-radiolysis in a Freon matrix at 77 K (lower part of Figure 2) generate the same species with $\lambda_{\max }=440 \mathrm{~nm}$ but in $n$-butyl chloride this transient is not quenchable with oxygen.

Figure 2

In the spectrum recorded after oxidation with $\mathrm{N}_{3}{ }^{\circ}$ the band at $440 \mathrm{~nm}$ occurs only as a minor constituent that arises with a rate constant of $8.0 \times 10^{8} \mathrm{M}^{-1} \mathrm{~s}^{-1}$. The major transient, which is 
formed with a rate constant of $3.3 \times 10^{8} \mathrm{M}^{-1} \mathrm{~s}^{-1}$ shows the same $335 \mathrm{~nm}$ band that is observed also after pulse radiolysis of aziridine 1 with $\mathrm{Tl}_{2} \mathrm{SO}_{4}$. Under an atmosphere of $\mathrm{N}_{2} \mathrm{O}: \mathrm{O}_{2}=4: 1$, this $335 \mathrm{~nm}$ absorption is completely quenched, so this transient is very sensitive to oxygen. We propose that this species is an adduct radical formed by attack of $\mathrm{OH}^{\bullet}$ onto a phenyl group of $\mathbf{1}$. In the spectrum obtained with $\mathrm{SO}_{4}{ }^{-}$as oxidant there is no absorption at $335 \mathrm{~nm}$ because the tert-butanol that is added in this experiment immediately traps all OH-radicals. This, and the fact that adducts of aromatic systems with OH-radicals generally show absorptions in this region, ${ }^{[22-24]}$ supports the assignment of the $335 \mathrm{~nm}$ transient as an adduct radical. In order to confirm this assignment we subjected a $0.1 \mathrm{~mm}$ solution of $\mathbf{1}$ in $\mathrm{N}_{2} \mathrm{O}$-saturated water at $\mathrm{pH} 8$ to pulse radiolysis. Thereby we detected also a major transient at $335 \mathrm{~nm}$ (Figure 3) while the $440 \mathrm{~nm}$ absorption apperars as a minor secondary transient by $\mathrm{OH}^{-}$elimination from the adduct radical. The same $\mathrm{OH}$ adduct radical may also be formed in the experiments with $\mathrm{Tl}_{2} \mathrm{SO}_{4}$ described above.

Figure 3

By comparison with the absorption spectrum of the radical cation of $N, N$-dimethyl aniline $\left(\mathrm{DMA}^{+\bullet}\right)$ which shows an intense band at $465 \mathrm{~nm},[22,25]$ we assign the $440 \mathrm{~nm}$ band of ionized 1 to the (ring closed) radical cation of N-phenylaziridine (a discussion of the electronic structure of $\mathbf{1}^{+\bullet}$ will be provided in Section 2.2).

1-Butyl-2-phenylaziridine 2a In the spectrum of $0.2 \mathrm{~mm}$ aziridine $\mathbf{2 a}$ in an aqueous solution containing $2 \mathrm{~mm}$ potassium peroxodisulfate a new strong absorption occurred at $380 \mathrm{~nm}$ and a flat, weak one at $550 \mathrm{~nm}$ (Figure 4). These bands rise concurrently, with a similar rate as that observed for the decay of the sulfate radical anion at $450 \mathrm{~nm}[26,27]\left(k=9.0 \times 10^{8} \mathrm{M}^{-1} \mathrm{~s}^{-1}\right)$,

and they are also quenchable by oxygen $\left(k=1.3 \times 10^{8} \mathrm{M}^{-1} \mathrm{~s}^{-1}\right)$. A similar pair of bands $\left(\lambda_{\max }\right.$ $=575$ and $390 \mathrm{~nm}$ ) was also observed on $\gamma$-radiolysis of aziridine $\mathbf{2 a}$ in a Freon matrix at 77 $\mathrm{K}$ (Figure 4, solid line). On pulse irradiation of $9 \mathrm{~mm} \mathbf{2 a}$ in $n$-butyl chloride, a different transient with a band at $325 \mathrm{~nm}$ was formed, which can also be quenched by oxygen but we have been unable to assess the identity of this species.

\section{Figure 4}

Evidently, these spectra are quite different from those found for the radical cations of $\mathrm{N}$ phenylaziridines, which should come as no surprise because 2a lacks the $N, N$-dialkylanilino 
chromophore which was found to be responsible for the $440-490 \mathrm{~nm}$ bands that are characteristic for the corresponding radical cations. However, calculations predict that C-phenylazirdines undergo facile ring opening to azomethine ylide radical cations on ionization (see below), so the chromophore that is responsible for the spectra in Figure 4 is of an altogether different nature in this case. Very similar spectra were obtained also for the corresponding Nmethyl as well as for the N-H derivative on $\gamma$-radiolysis in Freon glasses. [28]

\section{trans-2,3-Diphenylaziridines $3 a$ and $3 b$}

${ }^{60} \mathrm{Co}-\gamma$-radiolysis of $\mathbf{3 a}$ and $\mathbf{3 b}$ in a Freon marix at $77 \mathrm{~K}$ yields nearly indistinguishable spectra (shown in Figure 5), so we can assume that similar cations are formed. As will be shown below, 2,3-diphenylaziridines undergo spontaneous ring-opening on ionization to yield azomethine ylide radical cations of the same type as $\mathbf{2 a}$, cations which are characterized by their broad bands in the $500-800 \mathrm{~nm}$ range.

\section{Figure 5}

Conversely, the spectra obtained on pulse radiolysis of $8 \mathrm{~mm} \mathrm{3a}$ and $9 \mathrm{~mm} \mathbf{3 b}$ in $n$-butyl chloride are quite different in appearance (Figure 5). That obtained from $\mathbf{3 b}$ shows bands peaking at 430 and ca $700 \mathrm{~nm}$ which arise and decay with the same rate. The same bands are also observed if $\mathrm{SO}_{4}{ }^{-}$is used as an oxidant where they also build up with the same rate $(k=$ $\left.9.0 \times 10^{8} \mathrm{M}^{-1} \mathrm{~s}^{-1}\right)$ and are both quenched by oxygen $\left(k=7.9 \times 10^{7} \mathrm{M}^{-1} \mathrm{~s}^{-1}\right)$. Since the two bands coincide with those in the spectra obtaied after $\gamma$-radiolysis in Freon, we conclude that the same radical cation is formed in the two sets of experiments. In contrast to the radical cations of the $N$-aryl aziridines $\mathbf{1}, \mathbf{4 a}$, and $\mathbf{4 b}$ (see below), this one is, however, also quenchable with oxygen in $n$-butyl chloride. Similar to the case of $\mathbf{2 a}$ we cannot explain the oxygen quenchable transient absorbing at $330 \mathrm{~nm}$ after pulse radiolysis in butyl chloride.

In addition, there are pronounced shoulders at $480 \mathrm{~nm}(\mathbf{3 a})$ and $500 \mathrm{~nm}(\mathbf{3 b})$, respectively, the kinetics of which differ from that for the formation and decay of the 430 and $700 \mathrm{~nm}$ bands. Previous flash photolysis experiments in acetonitrile and methanol had given rise to bands at $480 \mathrm{~nm}(\mathbf{3 a})$ or $500 \mathrm{~nm}(\mathbf{3 b})^{[12]}$ which were assigned to the neutral azomethine ylides that are formed by ring opening of aziridines. ${ }^{[29]}$ Perhaps the same species are formed as minor products on pulse radiolysis in $\mathrm{BuCl}$ or $\gamma$-radiolysis in Freon. [30] 
In contrast, the spectrum obtained on pulse radiolysis of $\mathbf{3 a}$, either in $n$-butyl chloride or in aqueous peroxodisulfate solution, differs strongly from that found after $\gamma$-radiolysis in Freon. It shows four absorptions at 280, 320, 380 and $630 \mathrm{~nm}$ that appear with the same rate constant $\left(k=6.6 \times 10^{9} \mathrm{M}^{-1} \mathrm{~s}^{-1}\right)$ and are quenchable with oxygen $\left(k=5.8 \times 10^{8} \mathrm{M}^{-1} \mathrm{~s}^{-1}\right.$, the highest such rate constant observed in this study!) in the peroxodisulfate experiments. We also note that the major absorption at $380 \mathrm{~nm}$ is very intense $\left(\varepsilon=21^{\prime} 100 \mathrm{M}^{-1} \mathrm{~cm}^{-1}\right)$ compared to those of the oxidation products of the other aziridines $\left(\varepsilon=2000-4000 \mathrm{M}^{-1} \mathrm{~cm}^{-1}\right)$ that were identified in this study.

In order to identify the transient observed upon pulse radiolysis of $\mathbf{3 a}$ we measured the conductivity of an aqueous peroxodisulfate solution of this compound and compared it to a similar solution containing aziridine $\mathbf{3 b}$ (note that these solutions have a $\mathrm{pH}$ of 4.9 so the aziridines are present mostly in their protonated forms, $\mathbf{3} \mathbf{H}^{\mathbf{+}}$ ) After the pulse the conductivity was found to be much higher in the case of $\mathbf{3 a}$ than if the solution contained $\mathbf{3 b}$. This finding leads us to postulate that $\mathbf{3} \mathbf{a}^{+\bullet}$ undergoes spontaneous deprotonation to yield radical $\mathbf{6}$ (Scheme 2), a decay pathway that is not available to $\mathbf{3 b}^{+\bullet}$.

\section{Scheme 2}

We propose a ring opend structure for the $\mathbf{6}$ because (a) calculations predict that $\mathbf{3 a}^{+\bullet}$ undergoes spontaneous ring opening (see below) and (b) because the allylic radical 6 enjoys considerably more stabilization by the two terminal phenyl rings than an aziridinyl radical. Of course in $n$-butyl chloride, spontaneous deprotonation of $\mathbf{3 a}^{+\bullet}$ is not expected to occur because the proton cannot be solvated. We can see two possibilities for the formation of $\mathbf{6}$ under these conditions: either $\mathbf{3 a}^{+\bullet}$ is deprotonated by neutral $\mathbf{3 a}$, or $\mathbf{3 a}$ undergoes hydrogen atom loss on radiolysis in $n$-butyl chloride. A similar process was observed by Qin and Williams to occur on $\gamma$-irradition of parent aziridine in a $\mathrm{CF}_{2} \mathrm{ClCCl}_{2} \mathrm{~F}$-matrix at $114 \mathrm{~K}$ which led, next to the ring-opened azomethine ylid radical cation, to the aziridinyl radical.[20]

In aqueous solution $\mathbf{2}^{\mathbf{a}^{\boldsymbol{\bullet}}}$ and $\mathbf{3} \mathbf{b}^{+\bullet}$ are trapped faster by oxygen than the radical cations of the 1 -aryl aziridines and, in contrast to the latter, $\mathbf{3 b ^ { + }}{ }^{\bullet}$ is quenchable with oxygen even in $n$ butyl chloride. The fact that $\mathbf{3 b}$ was found to undergo [3+2] cycloadditions with various dipolarophiles under PET-conditions $[6,7,10-13]$ also speaks for a ring opened structure of the radical cation. 
1-Aryl-2-phenyl aziridines $\mathbf{4 a}$ and $\mathbf{4 b}$. On pulse radiolysis of an aqueous solution of $0.2 \mathrm{~mm}$ 1,2-diphenyl aziridine (4a) containing peroxodisulfate a transient absorbing at $440 \mathrm{~nm}$ builds up with a rate constant of $6.0 \times 10^{8} \mathrm{M}^{-1} \mathrm{~s}^{-1}$. This transient is quenchable with oxygen $(k=5.5$ $\times 10^{5} \mathrm{M}^{-1} \mathrm{~s}^{-1}$ ). Pulse radiolysis of a $9 \mathrm{mM}$ solution of $\mathbf{4 a}$ in $n$-butyl chloride also afforded a broad absorption with a maximum at $440 \mathrm{~nm}$ which is, however, not quenchable by oxygen. Additional evidence for the identification of this species is obtained by the results of $\gamma$-radiolysis in a Freon matrix at $77 \mathrm{~K}$ which leads to a spectrum with an intense band peaking at 445 $\mathrm{nm}$ (solid line in Figure 6). In addition, a broad band with $\lambda_{\max } \approx 650 \mathrm{~nm}$, similar to that observed after ionization of 1-butyl-2-phenyldiaziridine 2a, is observed. However, this latter band can be bleached separately by irradiation through a $590 \mathrm{~nm}$ cutoff filter, so it does not belong to the same species as the intense UV band. Apparently this second, unidentified species is not formed on pulse radiolysis in solution.

\section{Figure 6}

Aqueous peroxodisulfate spontaneously oxidizes 1-(p-methoxyphenyl)-2-phenyl aziridine (4b), even at room temperature, to yield a purple solution with a concomitant decrease of the $\mathrm{pH}$. Therefore $\mathbf{4 b}$ cannot be subjected to pulse radiolysis to generate its radical cation under controlled conditions. However, if $\mathrm{N}_{3}^{\bullet}$ is used as oxidant we observe a transient absorption at $470 \mathrm{~nm}$ which arises with a rate constant of $2.9 \times 10^{9} \mathrm{M}^{-1} \mathrm{~s}^{-1}$ and is quenched by oxygen $(k=$ $\left.1.5 \times 10^{7} \mathrm{M}^{-1} \mathrm{~s}^{-1}\right)$. Once again, pulse radiolysis of a $9 \mathrm{~mm}$ solution of aziridine $\mathbf{4 b}$ in $n$-butyl chloride results in a similar absorption which is, however, not quenchable with oxygen. A $480 \mathrm{~nm}$ band with a tail that extends to over $700 \mathrm{~nm}$ is observed after- $\gamma$-radiolysis of $\mathbf{4 b}$ in a Freon matrix at $77 \mathrm{~K}$.

\section{Figure 7}

The similarity in the kinetic and spectroscopic data of the oxidzed 1-phenyl and the 1-aryl-2phenyl aziridines indicates that the resulting radical cations retain a ring closed structure in all cases. This conclusion is confirmed by preparative studies which yielded no products from reactions with dipolarophiles, products that would have indicated that ring opening to azomethine ylide radical cations has occurred, under PET-conditions. [11]

\section{1,2,3-Triphenylaziridine 5}


This compound was only investigated by $\gamma$-radiolysis, but the results proved to be quite interesting: After radiolysis, a spectrum with a band peaking at $451 \mathrm{~nm}$, i.e. in the region where N-phenylaziridine radical cations absorb, was observed in addition to a broad, weak absorption between 500 and $700 \mathrm{~nm}$ (Figure 8a). After only three minutes of photolysis through a $715 \mathrm{~nm}$ cutoff filter, a much more intense spectrum arose (Figure 8b) which could in turn be bleached completely by irradiation at $>475 \mathrm{~nm}$ (Figure $8 \mathrm{c}$ ). This latter spectrum is similar to those observed after radiolysis of the 2,3-diphenylaziridines $\mathbf{3 a}$ and $\mathbf{3 b}$ which undergo spontaneous ring-opening on oxidation.

Thus, 5 appears to retain its ring-closed structure after ionization at $77 \mathrm{~K}$ but can be converted to its ring-opened azomethine ylide radical cation by subsequent photolysis, a unique behaviour in the series of phenyl substituted aziridines investigated in this study.

\section{Figure 8}

\subsection{Calculations}

In an effort to substantiate the conclusions we had reached from the above described experiments, and to understand the reasons for the different fate of the ionized aziridines and the electronic structure of the resulting transients, we carried out a comprehensive set of quantum chemical calculations whose results are presented and discussed in this section.

\section{N-phenylaziridine (1)}

On ionization of $\mathbf{1}$ an electron is removed from the HOMO depicted on the right hand side of Figure 9. Contrary to that of the iso- $\pi$-electronic benzyl anion, this MO is antibonding between the phenyl ring and the $\mathrm{N}$ atom, hence we expect this bond to be strengthened in the radical cation of 1 . B3LYP calculations confirm that on ionization this bond assumes partial double bond character which expresses itself also in the fact that the aziridine and the phenyl ring are nearly coplanar in $\mathbf{1}^{+\bullet}$ (Figure 9). In contrast, the length of the bonds in the aziridine moiety are hardly affected by ionization which indicates that ring-opening will not be much easier in the radical cation than in the neutral aziridine. 
The photoelectron spectrum of $\mathbf{1}^{[31,32]}$ shows two more bands within $3 \mathrm{eV}$ of the first, the second of which lies only $1 \mathrm{eV}$ above the first. Hence, the observed absorption bands of $\mathbf{1}^{+\bullet}$ at $440 \mathrm{~nm}(2.8 \mathrm{eV})$ must correspond to $\mathrm{D}_{0} \rightarrow \mathrm{D}_{2}$ excitation. Indeed, TD-B3LYP excited state calculations predict another, very weak transition at $690 \mathrm{~nm}$ which corresponds to HOMO-1 $\rightarrow$ HOMO excitation (the observed $\mathrm{D}_{0} \rightarrow \mathrm{D}_{2}$ transition, which involves HOMO-2 $\rightarrow$ HOMO and $\mathrm{HOMO} \rightarrow$ LUMO excitation is predicted at $400 \mathrm{~nm}$ ).

\section{Scheme 3}

If enforced (e.g. by lengthening the $\mathrm{C}-\mathrm{C}$ bond in the aziridine), ring opening of the radical cation proceeds in a nonconcerted conrotatory fashion. According to B3LYP, the transition state for this reaction lies $33 \mathrm{kcal} / \mathrm{mol}$ above $\mathbf{1}^{+\bullet}$, but the process leading to the 2 -phenylazomethine ylide radical cation $\mathbf{7}^{+\bullet}$ (see Scheme 3 ) is nearly thermoneutral. This contrasts with the parent aziridine radical cation where the same level of theory predicts a barrier of only 10.1 and an exothermicity of $33.6 \mathrm{kcal} / \mathrm{mol}$.28] To understand the influence that the $\mathrm{N}$ phenyl ring has on the thermochemistry and the kinetics of this process we calculated the barriers for rotation of this phenyl ring in $\mathbf{1}^{+\bullet}$, at the transition state, and in $\mathbf{7}^{\mathbf{+}^{\bullet}}$. Whereas in $\mathbf{1}^{+\bullet}$ it is $26.3 \mathrm{kcal} / \mathrm{mol}$, thus testifying to the substantial resonance stabilization of this cation by the phenyl ring, it falls to $9.6 \mathrm{kcal} / \mathrm{mol}$ at the transition state (i.e. $16.7 \mathrm{kcal} / \mathrm{mol}$ of resonance energy is lost at this point). In $7^{+\bullet}$ the phenyl ring is already twisted by $53^{\circ}$ and bringing it into a perpendicular position equires only $0.6 \mathrm{kcal} / \mathrm{mol}$. This comes as no surprise, because the phenyl ring is attached to a nodal position of the allylic HOMO of $\mathbf{7}^{+\bullet}$ where it cannot exert a stabilizing influence. Thus our conclusion that $\mathbf{1}$ retains its ring-closed structure on ionization is fully confirmed by the calculations.

\section{N-methyl-2-phenylaziridine $2 b$}

If a phenyl ring is attached to a $\mathrm{C}$ rather than the $\mathrm{N}$-atom of the aziridine, the situation changes completely compared to that in $\mathbf{1}$. For reasons of compuational economy calculations were carried out on the 1-methyl rather than the 1-butyl derivative (the cations that result from the two compounds have virtually indistinguishable spectra $\left.{ }^{[28]}\right)$. Now the HOMO arises through interaction of the benzene moiety with the symmetric Walsh-MO in the three-membered ring (cf. Figure 10). 
The geometry changes on ionization are in accord with expectations from the nodal properties of the MO from which the electron is removed (Figuer 10): The aziridine $\mathrm{C}-\mathrm{C}$ bond lengthens by $0.12 \AA$, which will facilitate the cleavage of this bond, whereas the azridinephenyl bond shortens by $0.04 \AA$.

Indeed, the transition state for ring-opening, which occurs again in a conrotatory fashion, is found to lie only $4 \mathrm{kcal} / \mathrm{mol}$ above $2 \mathbf{b}^{+\bullet}$, and the process is exothermic by $25 \mathrm{kcal} / \mathrm{mol}$, i.e. almost as much as in the parent compound. An intrinsic reaction coordinate calculation form the transition state leads to the exoisomer of the C-phenyl-N-methyl azomethine ylide radical cation $\mathbf{8}^{+\bullet}$ although a separate calculation shows that the endo-conformer lies even 0.6 $\mathrm{kcal} / \mathrm{mol}$ lower in energy, in spite of the twisting of the phenyl ring that results from steric interactions in this case.

To gain insight into the role of the phenyl ring in $\mathbf{2} \mathbf{b}$ we computed again the barriers for twisting that ring to a position that is perpendicular to that which it assumes at the optimized geometries of $\mathbf{2 b}^{+\bullet}$, the transition state for ring opening, and $\mathbf{8}^{+\bullet}$ : this processs requires only $7.8 \mathrm{kcal} / \mathrm{mol}$ in $\mathbf{2 b}^{+\bullet}$ and $8.0 \mathrm{kcal} / \mathrm{mol}$ in $\mathbf{8}^{+\bullet}$, but $18.7 \mathrm{kcal} / \mathrm{mol}$ at the transition state. Thus, in contrast to $\mathbf{1}^{+\bullet}$, the phenyl ring has a $11 \mathrm{kcal} / \mathrm{mol}$ greater stabilizing effect at the transition state than in the reactant in the case of $\mathbf{2 b}^{+\bullet}$, which readily explains why the barrier for ring opening is so much lower in this case. Apparently this barrier is too low to even prevent ring opening from occurring at $77 \mathrm{~K}$.

Next we addressed the question whether the spectra shown in Figure 4 are compatible with those expected for $\mathbf{8}^{+\bullet}$. In this case, the TD-B3LYP method provided quite unsatisfactory results, so we turned to the CASSCF/CASPT2 method to model the excited states. Thereby we distinguished between the two isomers which are expected to have slightly different spectra. The results of these calculations are summarized in Table 1 which shows that the most important transition in $\mathbf{8}^{+\bullet}$ involve the allylic azomethine ylid moiety (MOs 34, 36, and 37 in Figure 11). On the whole, the spectrum that is predicted for the exo-isormer is in better accord with the experimental one than that computed for the endo-isomer. Together with the IRC calculation mentioned above, this seems to indicate that it is indeed the exo-isomer of $\mathbf{8}^{+\bullet}$ which is formed in the ring-opening of $\mathbf{2 b}^{+\bullet}$. 


\section{N-Methyl-2,3-diphenylaziridine 3c}

In view of the above conclusions with regard to 2-phenylaziridine, it certainly comes as no surprise that 2,3-diphenylaziridines undergo almost barrierless ring opening on oxidation. Actually it turned out to be quite tricky to prevent the radical cation of the model system 3c from relaxing spontaneously to the azomethine ylid radical cation $\mathbf{9}^{+\bullet}$, and to find a transition state for this process. On ionization of $\mathbf{3 c}$, the $\mathrm{C}-\mathrm{C}$ bond in the aziridine moiety lengthens to $1.86 \AA$ and a barrier of less than $1 \mathrm{kcal} / \mathrm{mol}$ remains to effect full cleavage of this bond to yield the endo-exo-isomer of $\mathbf{9}^{+\bullet}$ where both phenyl rings are twised by ca. $20^{\circ}$ relative to the $\mathrm{C}-\mathrm{N}-\mathrm{C}$ plane of the azomethine ylide moiety. Due to the presence of phenyl rings on both azridine carbon atoms, the SOMO is centered even more strongly in the symmetric WalshMO of the three membered ring than in the 2-phenylaziridine (Fig 12).

\section{Figure 12}

Unfortunately, $\mathbf{9}^{+\bullet}$ proved to be too large to be amenable to CASSF/CASPT2 calculations of its excited states, so we had to resort to the more economical TD-DFT method to model the electronic spectrum of $\mathbf{9}^{+\bullet}$. Although the resulting predictions are not in such good quantitative accord with the experimental spectra of ionized 3a and $\mathbf{3 b}$ shown in Figure 5 they show that the main ransitions are of similar nature as those of $\mathbf{8}^{+\bullet}$ above, i.e. they also involve mainly MOs that are centered on the allylic azomethine ylide moiety. In agreement with the experimental spectra of ionized 3a and 3b, TD-B3LYP predicts those spectra to be dominated by two excitations around 2 and $3 \mathrm{eV}$, respectively, with the latter being about 4 times more intense than the former. Perhaps the shoulder at $510 \mathrm{~nm}$ is in part due to the two weak transitions that are predicted around $2.6 \mathrm{eV}$ and that correspond to charge transfer from the benzene to the allyl moieties of $\mathbf{9}^{+\bullet}$. In any event, the calculations of the potential energy surface and the results in Table 2 leave no doubt that the spectra in Figure 5 are those of $9^{+\bullet}$, although we can make no prediction with regard to the conformations around the allylic $\mathrm{N}-\mathrm{C}$ bonds in this case.

\section{1,2-Diphenyl aziridine (4a)}


We have seen above that a phenyl ring attached to the $\mathrm{N}$-atom of an aziridine effectively prevents ring opening on ionization, whereas a phenyl ring attached to a $\mathrm{C}$-atom promotes it. Therefore we were anxious to see what theory would tell us about the fate of 1,2-diphenylazriridine, $\mathbf{4 a}$.

\section{Figure 13}

As it turned out, the influence of the N-phenyl ring dominates over that of the C-phenyl ring, i.e. ionization occurs from an MO that is similar to the HOMO of 1 (Figure 13, cf. Figure 9). Consequently, the geometry changes on ionization of $\mathbf{4 a}$ are also very similar to those suffered by $\mathbf{1}$, i.e. a shortening of the $\mathrm{N}$-phenyl bond accompanied by an planarization of the $\mathrm{N}$ atom (the angle between the plane of the aziridine ring and the C-phenyl bond decreases from $49^{\circ}$ to $25^{\circ}$, while the inversion barrier disappears nearly). In particular, the distal C-C bond in the aziridine ring is hardly affected by ionization.

Neverthelesss the C-phenyl ring does not remain without an effect on the reactivity of 4a: due to the stabilization of the product, the ring opening reaction (which had been nearly thermoneutral in $\mathbf{1}^{+\bullet}$ ) becomes exothermic by ca $10 \mathrm{kcal} / \mathrm{mol}$ while the barrier decreases to 19.4 $\mathrm{kcal} / \mathrm{mol}$ in $\mathbf{4 a}^{+\bullet}$, i.e. it lies almost midway between those in $\mathbf{1}^{+\bullet}(33 \mathrm{kcal} / \mathrm{mol})$ and in $\mathbf{2}^{+\bullet}$ and close to that in $\mathbf{3 a}^{+\bullet}\left(16 \mathrm{kcal} / \mathrm{mol}^{[28]}\right)$. Thus, at the transition state for ring opening, the effects of the two phenyl rings appear to cancel almost completely.

Due to the great similarity of the spectra observed after ionization of $\mathbf{4 a}$ and of $\mathbf{1}$, we refrained from carrying out electronic structure calculations on $\mathbf{4 a}^{+\bullet}$. Suffice it to say that the "reactive" state where the unpaired electron resides in the symmetric Walsh MO of the aziridine lies almost $1 \mathrm{eV}$ above the state where the SOMO corresponds to that shown in Figure 9, and the transition to that state is very weak, so it does not interfere with the electronic structure of $\mathbf{4} \mathbf{a}^{+\bullet}$.

\section{1,2,3-Triphenylaziridine 5}

The HOMO of $\mathbf{5}$ from which ionization occurs is once again centered on the N-phenyl moiety, as in $\mathbf{1}$ and $\mathbf{4 a}$. Thus, it is not surprising that the structure of the aziridine ring changes very little on ionization. However, the phenyl rings that are attached to the C-atoms of the aziridine begin to show their influence on the way to the product in that the activation energy for ring opening is only $5.43 \mathrm{kcal} / \mathrm{mol}$ (up $4.5 \mathrm{kcal} / \mathrm{mol}$ from 2,3-diphenylaziridine radical 
cation $3 \mathbf{c}^{+\bullet}$, due to the influence of the $\mathrm{N}$-phenyl ring) and the process is exothermic by 17.9 $\mathrm{kcal} / \mathrm{mol},{ }^{[33]}$ halfway between the 1,2-diphenyl- and 2,3-diphenylziridine radical cations, $\mathbf{4 a}^{+\bullet}$ and $\mathbf{3 \mathbf { c } ^ { + \bullet }}$

\section{Conclusions}

In conclusion we successfully generated and identified the radical cations that are formed on oxidation of different phenyl-substituted aziridines by pulse radiolysis in aqueous solution containing different oxidants or in $n$-butyl chloride at room temperature, and by $\gamma$-radiolysis in a Freon matrix at $77 \mathrm{~K}$. As it turns out, the position(s) of the phenyl substituent(s) determines the fate of the incipient azridine radical cations: if the $\mathrm{N}$ atom carries a phenyl ring, this effectively protects the aziridine radical cation from decaying to an azomethine ylide radical cation, due to the benzylic resonance stabilization that prevails in $\mathrm{N}$-phenylazridine radical cations. The benzylic $\mathrm{Ph}-\mathrm{N}^{+\bullet}$ chromophore is also responsible for the intense $\mathrm{D}_{0} \rightarrow \mathrm{D}_{2}$ transitions in the $440-480 \mathrm{~nm}$ range that are characteristic for the ring-closed aziridine radical cations.

In contrast, phenyl rings attached to the $\mathrm{C}$-atoms of the aziridine lower the barrier for ring opening, to the extent that the process becomes nearly activationless in 2,3-diphenylaziridine radical cation. This is mainly due to the preferential stabilization of the allylic azomethine ylide radical cations by phenyl rings attached to their terminal C-atoms. This chromophore gives also rise to intense near-UV transitions, but in addition it distinguishes itself by a weak broad band at 500-800 $\mathrm{nm}$. In addition the two types of radical cations can be distinguished by their reactivity towards oxygen: In aqueous solution, the ring-opened azomethine ylide radical cations are quenched with a higher rate than the ring-closed aziridine radical cations, and in $n$-butyl chloride the former are not quenchable by $\mathrm{O}_{2}$ (in contrast to the latter).

Quantum chemical calculations support the above conclusions and helped to assign the observed spectra. They also allow to understand the influence of phenyl rings attached to different positions of aziridine radical cations on their reactivity. In Figure 14 we summarize the results that pertain to the ring-opening reactions of the various types of azridine radical cations that were investigated in the present study. 
Figure 14

The thermochemistry of the ring opening of the different aziridine radical cations is compared to that of the parent azirdine radical cation and the N-methyl derivative, calculated also at the B3LYP/6-31G* level.[28]

Upon pulse radiolysis in aquous solution the radical cation of 2,3-diphenylaziridine was found to undergo spontaneous deprotonation to form an allylic radical, while in $n$-butyl chloride $\mathrm{H}$-abstraction from the aziridine generates the same species. We also provided an additional access to aziridine radical cations upon photolysing aqueous solutions of aziridines with an excimer laser for $\mathbf{2 a}, \mathbf{3 b}, \mathbf{4 a}$ and $\mathbf{4 b}$.

\section{Experimental}

\section{Starting materials.}

1-Phenyl aziridine (1) ${ }^{[34]}$, 1,2-diphenyl aziridine (4a) ${ }^{[35]}$, 1-(p-methoxyphenyl)-2-phenyl aziridine (4b) ${ }^{[35]}$ and trans-2,3-diphenylaziridine (3a) ${ }^{[36]}$ were prepared by reported procedures.

Preparation of 1-butyl-2-phenyl aziridine (2a).[11, 37] Starting with commercial available styrol oxide the corresponding $\beta$-amino alcohol is prepared according to the procedure of Chapman and Triggle. [38] The formation of 1-butyl-2-phenyl aziridine occured as described by Okada et al.[37]

Preparation of 1-butyl-trans-2,3-diphenyl aziridine (3b).[11] Using trans-stilbene as starting material epoxidation with MCPBA formed the corresponding trans-stilbene oxide in yields of $75 \%$. Following the procedure of Deyrup and Moyer[39] the epoxide is opened to the $\beta$-amino alcohol. The cyclization as described above[37] formed 1-butyl-trans-2,3diphenyl aziridine in yields of $58 \%$.

All spectroscopical data of the aziridines are published.[11]

\section{Pulse radiolysis}

For pulse radiolysis, 0.4-2 $\mu$ s electron pulses from a $3 \mathrm{MeV}$ van de Graaff accelerator were used at dose rates of 30-3000 rad per pulse. $\mathrm{N}_{2} \mathrm{O}$-, argon- or oxygen-saturated solutions containing 0.1 up to $9 \mathrm{~mm}$ aziridine were flowed through a quartz cell (20 mm path length) while 
being irradiated. As precursor of the oxidants we used thallium(I) sulfate, potassium peroxodisulfate and sodium azide in an exess of 10 times of the concentration of the aziridine.

Upon radiolysis in water $\mathrm{OH}$-radicals and solvated electrons are generated. ${ }^{40-42]}$ Using a $\mathrm{N}_{2} \mathrm{O}$-saturated solution the amout of the $\mathrm{OH}$-radicals is increasd following the reaction: $\mathrm{N}_{2} \mathrm{O}$ $+\mathrm{H}_{2} \mathrm{O} \rightarrow \mathrm{N}_{2}+\mathrm{OH}^{-}+\mathrm{OH}^{\bullet}{ }^{[43]}$ The $\mathrm{OH}$-radical is important for the formation of the oxidants. In the case of thallium(I) sulfate the oxidizing species is generated according to the reaction: $\mathrm{Tl}^{+}+\mathrm{OH}^{\bullet} \rightarrow \mathrm{TlOH}^{\bullet+}$.[21] Using sodium azide, the $\mathrm{N}_{3}{ }^{\bullet}$ is formed via $\mathrm{N}_{3}{ }^{-}+\mathrm{OH}^{\bullet} \rightarrow$ $\mathrm{N}_{3} \cdot \mathrm{OH}^{-}{ }^{[44]}$ Concerning the measurements with peroxodisulfate, the produced solvated electrons are used to create the sulfate radical anion: $\mathrm{S}_{2} \mathrm{O}_{8}{ }^{{ }^{-}}+\mathrm{e}^{-} \rightarrow \mathrm{SO}_{4}{ }^{{ }^{-}}+\mathrm{SO}_{4}{ }^{--}{ }^{[}[26,27] \mathrm{In}$ this case the $\mathrm{OH}$-radicals can disturb, therefore tert-butanol is added in order to trap the $\mathrm{OH}$ radicals. $[23,45]$ Pulsing in $n$-butyl chloride, solvent radical cations are formed on direct ionization. $[25,46]$ All these reactive species can oxidize the substrates in a one elektron transfer reaction. The corresponding substrate radical cations are formed.

\section{$\gamma$-radiolysis}

$\gamma$-radiolysis of $10^{-2}-10^{-3} \mathrm{M}$ solutions of organic samples in Freons at $77 \mathrm{~K}$ constitutes a very clean way of generating radical cations under conditions where they persist for hours. ${ }^{[46]}$ For the present experiments we employed a 1:1 mixture of $\mathrm{CFCl}_{3}$ and $\mathrm{CF}_{2} \mathrm{BrCF}_{2} \mathrm{Br}^{[47]}$ which form a transparent glass at $77 \mathrm{~K} .{ }^{[48]}$ Samples were exposed to a total dose of ca $5 \mathrm{kSv}$ of ${ }^{60} \mathrm{Co}$ radiation (1.173 and 1.332 MeV) in a Gammacell 220 charged with ca $450 \mathrm{TBq}$. Electronic absorption spectra were recorded on a Perkin Elmer Lambda 900 instrument.

\section{Quantum chemical calculations}

The geometries of all species except the singlet nitrenes were optimized by the B3LYP density functional method $[49,50]$ as implemented in the Gaussian program package, ${ }^{[51,52]}$ using the $6-31 \mathrm{G}^{*}$ basis set. All stationary points were characterized by second derivative calculations.

For the ylid radical cation, $\mathbf{8}^{+\bullet}$ that results from oxidative ring opening of 1-methyl-2-phenyldiazririne 3c, excitation energies and oscillator strenghts were calculated by the CASSCF/ CASPT2 procedure[53] using the ANO/S basis set,[54] at the B3LYP/6-31G* optimized 
geometries of the radical cations. The active space that was employed in the CASSCF calculations is indicted in Table 1 where the results are listed. Level shifts [55] had to be applied to eliminate intruder states in the CASPT2 runs for all excited states under consideration, but we checked carefully that no artefacts were introduced by this technique. Under this condition, the weight of the zero-order CASSCF wavefunction in the PT2 expansion was between 0.7 and 0.72 for all states. All CASSCF/CASPT2 calculations were performed with the Molcas program. [56]

For the diphenylaziridines, it was imposssible to carry out CASSCF/CASPT2 calculations so we resorted to the more economical time-dependent response theory, ${ }^{[57]}$ where the poles and the residues of the frequency-dependent polarizability are calculated, whereby the former correspond to vertical excitation energies and the latter to oscillator strengths. We employed the density-functional based implementation of this method (TD-DFT) ${ }^{[58]}$ using again the B3LYP functional and the 6-31G* basis set as described above.

Acknowledgment. Support provided by the Deutsche Forschungsgemeinschaft and the Fonds der Chemischen Industrie is gratefully acknowledged. T.B. and B. M are grateful for support by the Swiss National Science Foundation (project No. 2000-067881.02). C. G. thanks the Studienstiftung des deutschen Volkes for a scholarship.

\section{References and Notes}

[1] J. Backes in Methoden der Organischen Chemie (Houben-Weyl), Vol. E 16c, (Eds.: D. Klamann) Thieme, Stuttgart 1992, pp. 370-677.

[2] J. A. Deyrup in: Small Ring Heterocycles, Vol. Part 1, (Eds.: A. Hassner) John Wiley \& Sons, New York 1983, pp. 1-214.

[3] R. Huisgen, Angew. Chem. 1963, 75, 604.

[4] J. W. Lown, Rec. Chem. Prog. 1971, 32, 51.

[5] R. Huisgen in 1,3 Dipolar Cycloaddition Chemistry, Vol. 1, (Eds.: A. Padwa) John Wiley \& Sons, New York 1984, pp. 1-176.

[6] V. Caer, A. Laurent, E. Laurent, R. Tardevil, Z. Cebulska, R. Bartnik, Nouv. J. Chim. 1987, 11,351 . 
[7] T. Brigaud, E. Laurent, R. Tardevil, Z. Cebulska, R. Bartnik, J. Chem. Research (S) 1994, 8,330 .

[8] C. Gaebert, Diploma Thesis, Westfälische Wilhelms-Universität, Münster 1994.

[9] C. Gaebert, PhD Thesis, Westfälische Wilhelms-Universität, Münster 1997.

[10] C. Gaebert, J. Mattay, J. Inf. Record. 1996, 23, 3-6.

[11] C. Gaebert, J. Mattay, Tetrahedron 1997, 53, 14297.

[12] C. Gaebert, C. Siegner, J. Mattay, M. Toubartz, S. Steenken, J. Chem. Soc., Perkin Trans. 2 1998, 12, 2735.

[13] C. Siegner, C. Gaebert, J. Mattay, S. Steenken, J. Inf. Record. 1998, 24, 253.

[14] J. L. Holmes, J. K. Terlouw, Can. J. Chem. 1976, 54, 1007.

[15] A. Maquestiau, Y. van Haverbeke, R. Flammang, A. Menu, Bull. Soc. Chim. Belge 1979, 88, 53.

[16] M. H. Lien, A. C. Hopkinson, Can. J. Chem. 1984, 62, 922.

[17] A. P. Schaap, G. Prasad, S. D. Gagnon, Tetrahedron Lett. 1983, 24, 3047.

[18] A. P. Schaap, S. Siddiqui, G. Prasad, E. Palomino, L. Lopez, J. Photochem. 1984, 25, 167.

[19] A. P. Schaap, G. Prasad, S. Siddiqui, Tetrahedron Lett. 1984, 25, 3035.

[20] X.-Z. Qin, F. Williams, J. Phys. Chem. 1986, 90, 2292.

[21] P. O'Neill, D. Schulte-Frohlinde, J. Chem. Soc. Chem. Commun. 1975, 387.

[22] H. Christensen, Int. J. Radiat. Phys. Chem. 1972, 4, 311-333.

[23] H. Christensen, K. Sehested, E. J. Hart, J. Phys. Chem 1973, 77, 983.

[24] P. O'Neill, S. Steenken, D. Schulte-Frohlinde, J. Phys. Chem. 1975, 79, 2773.

[25] T. Shida, W. H. Hamill, J. Chem. Phys. 1966, 44, 2369.

[26] E. Heckel, A. Henglein, B. G., Ber. Bunsenges. Phys. Chem. 1966, 70, 149.

[27] L. Dogliotti, E. Hayon, J. Phys. Chem. 1967, 71, 2511.

[28] B. Müller, PhD thesis, University of Fribourg, Fribourg, Switzerland 2000.

[29] Interestingly, laser flash photolyis of $\mathbf{3 b}$ in a 1:1 mixture of acetonitrile and water gave also rise to a band at $430 \mathrm{~nm}$ (in contrast to the spectra observed previously in pure acetonitrile or methanol), next to those of the azomethine ylide at $500 \mathrm{~nm}$ and a 280 $\mathrm{nm}$ band that was assigned to an iminium ion obtained by protonation of the 
azomethine ylide. Thus it appears that in the presence of water aziridine radical cations and their ring-opening products can also be formed by flash photolysis.

[30] The bands at 480 and $500 \mathrm{~nm}$ persist on radiolysis of oxygen-saturated $\mathrm{BuCl}$ solutions, where the radical cations are not formed. The species responsible for these bands are thererfore not very sensitive to molecular oxygen, in accord with their assignment to neutral azomethine ylides.

[31] R. J. Lichter, K. Crimaldi, D. A. Baker, J. Org. Chem. 1982, 47, 3524.

[32] K. N. Houk, S. Searles, M. D. Rozeboom, S. E. Seyedrezai, J. Am. Chem. Soc. 1982, $104,3448$.

[33] An intrinsic reaction coordinate calculation from the transition state for ring opening of 5 leads to the exo-exo-isomer of the triphenylazomethine ylide radical cation which is, however easily converted into the more stable exo-endo-isomer.

[34] H. W. Heine, B. L. Kapur, C. S. Mitch, J. Am. Chem. Soc. 1954, 76, 1173.

[35] V. Franzen, H. E. Driesen, Chem. Ber. 1963, 96, 1881.

[36] D. Tanner, C. Birgersson, A. Gogoll, Tetrahedron 1994, 50, 9797.

[37] I. Okada, K. Ichimura, R. Sudo, Bull. Chem. Soc. Jpn. 1970, 43, 1185.

[38] N. B. Chapman, D. J. Triggle, J. Chem. Soc. 1963, 1385.

[39] J. A. Deyrup, C. L. Moyer, J. Org. Chem. 1969, 34, 175.

[40] A. Henglein, W. Schnabel, J. Wendenburg, Einführung in die Strahlenchemie, Verlag Chemie, Weinheim 1969.

[41] I. G. Draganic, Z. D. Draganic, The Radiation Chemistry of Water, Academic Press, New York 1971.

[42] R. W. T. Spinks, R. J. Woods, An Introduction to Radiation Chemistry, Wiley, New York 1990.

[43] J. H. Baxendale, M. A. Rodgers, Chem. Soc. Rev. 1978, 7, 235.

[44] Z. B. Alfassi, R. H. Schuler, J. Phys. Chem. 1985, 89, 3359.

[45] E. Bothe, D. J. Deeble, D. G. E. Lemaire, R. Rashid, M. N. Schuchmann, H.-P. Schuchmann, D. Schulte-Frohlinde, S. Steenken, C. von Sonntag, Radiat. Phys. Chem. 1990, 36, 149-154.

[46] T. Shida, Electronic Absorption Spectra of Radical Ions, Elsevier, Amsterdam 1988.

[47] A. Grimison, G. A. Simpson, J. Phys. Chem. 1968, 72, 1776.

[48] C. Sandorfy, Can. J. Spectrosc. 1965, 10, 85. 
[49] A. D. Becke, J. Chem. Phys. 1993, 98, 5648.

[50] C. Lee, W. Yang, R. G. Parr, Phys. Rev. B 1988, 37, 785.

[51] M. J. Frisch, G. W. Trucks, H. B. Schlegel, G. E. Scuseria, M. A. Robb, J. R. Cheeseman, V. G. Zakrzewski, J. A. Montgomery, R. E. Stratmann, J. C. Burant, S. Dapprich, J. M. Millam, A. D. Daniels, K. N. Kudin, M. C. Strain, O. Farkas, J. Tomasi, V. Barone, M. Cossi, R. Cammi, B. Mennucci, C. Pommelli, C. Adamo, S. Clifford, J. Ochterski, G. A. Petersson, P. Y. Ayala, Q. Cui, K. Morokuma, D. K. Malick, A. D. Rabuck, K. Raghavachari, J. B. Foresman, J. Cioslowski, J. V. Ortiz, B. B. Stefanov, G. Liu, A. Liashenko, P. Piskorz, I. Komaromi, R. Gomperts, R. L. Martin, D. J. Fox, T. Keith, M. A. Al-Laham, C. Y. Peng, A. Nanayakkara, M. Challacombe, P. M. W. Gill, B. G. Johnson, W. Chen, M. W. Wong, J. L. Andres, C. Gonzales, M. Head-Gordon, E. S. Repogle, J. A. Pople, , Gaussian, Inc., Pittsburgh, PA 1998.

[52] B. G. Johnson, P. M. W. Gill, J. A. Pople, J. Chem. Phys. 1993, 98, 5612.

[53] K. Andersson, B. O. Roos in Modern Electronic Structure Theory, Vol. Part 1, Vol. 2, (Eds.: World Scientific Publ. Co., Singapore 1995, pp. 55.

[54] K. Pierloot, B. Dumez, P.-O. Widmark, B. O. Roos, Theor. Chim. Acta. 1995, 90, 87.

[55] B. O. Roos, K. Andersson, M. P. Fülscher, L. Serrano-Andrés, K. Pierloot, M. Merchan, V. Molina, J. Mol. Struct (THEOCHEM) 1996, 388, 257.

[56] K. Andersson, M. Barysz, A. Bernhardsson, M. R. A. Blomberg, D. L. Cooper, T. Fleig, M. P. Fülscher, C. d. Graaf, B. A. Hess, G. Karlström, R. Lindh, P.-Å. Malmqvist, P. Neogrády, J. Olsen, B. O. Roos, A. J. Sadlej, M. Schütz, B. Schimmelpfennig, L. Seijo, L. Serrano-Andrés, P. E. M. Siegbahn, J. Stålring, T. Thorsteinsson, V. Veryazov, P.-O. Widmark, , University of Lund, Sweden 2000.

[57] M. E. Casida in Recent Advances in Density Functional Methods, part I, (Eds.: D. P. Chong) World Scientific, Singapore 1995, pp. 155.

[58] R. E. Stratmann, G. E. Scuseria, M. J. Frisch, J. Chem. Phys. 1998, 109, 8218. 


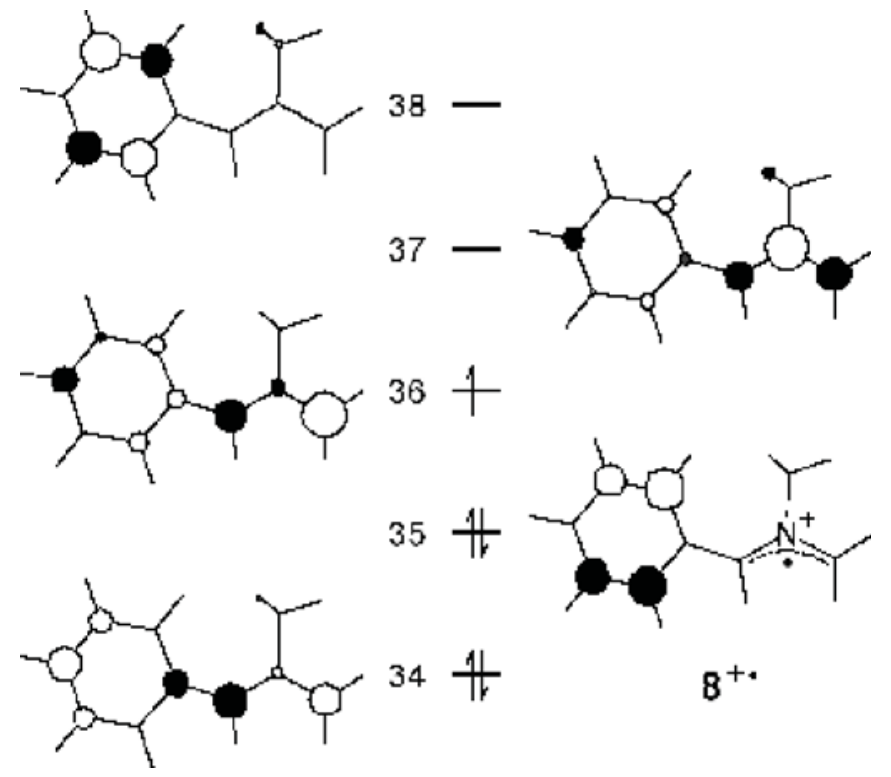

Figure 12

Table 1: Calculated electronic transitions of $\mathbf{8}^{+}$using the CASPT2 method

\begin{tabular}{|c|c|c|c|c|c|c|c|}
\hline \multirow{2}{*}{ isomer } & \multirow[b]{2}{*}{ states } & \multicolumn{2}{|c|}{---- experiment --- } & \multicolumn{3}{|c|}{--- CASPT2 --- } & \multirow{2}{*}{$\begin{array}{l}\text { CASSCF } \\
\text { configurations }^{b}\end{array}$} \\
\hline & & {$[\mathrm{nm}]$} & {$[\mathrm{eV}]$} & {$[\mathrm{nm}]$} & {$[\mathrm{eV}]$} & $f^{a}$ & \\
\hline \multirow[t]{8}{*}{ exo } & $1^{2} \mathrm{~A}^{\prime \prime}$ & - & - & - & - & - & $75 \%(36)^{1}$ \\
\hline & $2^{2} \mathrm{~A}^{\prime \prime}$ & 583 & 2.12 & 584 & 2.12 & 0.028 & $44 \% 36 \rightarrow 37$ \\
\hline & & & & & & & $20 \% 34 \rightarrow 36$ \\
\hline & $3^{2} \mathrm{~A}^{\prime \prime}$ & (440 sh) & $(2.82)$ & 484 & 2.56 & 0.002 & $55 \% 35 \rightarrow 36$ \\
\hline & & & & & & & $10 \% 34 \rightarrow 36$ \\
\hline & $4^{2} \mathrm{~A}^{\prime \prime}$ & 398 & 3.12 & 396 & 3.13 & 0.252 & $28 \% 34 \rightarrow 36$ \\
\hline & & & & & & & $19 \% 36 \rightarrow 38$ \\
\hline & & & & & & & $10 \% 36 \rightarrow 37$ \\
\hline \multirow[t]{8}{*}{ endo } & 1 & - & - & - & - & - & $77 \%(36)^{1}$ \\
\hline & 2 & 583 & 2.12 & 566 & 2.19 & 0.010 & $31 \% 34 \rightarrow 36$ \\
\hline & & & & & & & $27 \% 36 \rightarrow 37$ \\
\hline & & & & & & & $10 \% 36 \rightarrow 39$ \\
\hline & 3 & $(440 \mathrm{sh})$ & 2.82 & 485 & 2.56 & 0.002 & $62 \% 35 \rightarrow 36$ \\
\hline & 4 & 398 & 3.12 & 407 & 3.05 & 0.129 & $23 \% 34 \rightarrow 36$ \\
\hline & & & & & & & $17 \% 36 \rightarrow 37$ \\
\hline & & & & & & & $16 \% 36 \rightarrow 40$ \\
\hline
\end{tabular}

${ }^{a}$ Oscillator strength for electronic transition. ${ }^{b}$ Active space: 9 electrons in 5 occupied +4 virtual MOs. The most important of those are shown in Figure 11 . 


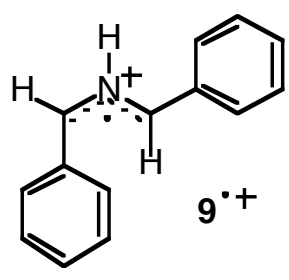

Table 2: Calculated electronic transitions of endo-exo-9 ${ }^{+}$using the TD-B3LYP method

\begin{tabular}{|c|c|c|c|c|c|c|}
\hline \multirow[b]{2}{*}{ states } & \multicolumn{2}{|c|}{--- experiment ${ }^{a}$--- } & \multicolumn{3}{|c|}{----------TD-B3LYP -------- } & \multirow[t]{2}{*}{ configurations $^{b}$} \\
\hline & {$[\mathrm{nm}]$} & {$[\mathrm{eV}]$} & {$[\mathrm{nm}]$} & {$[\mathrm{eV}]$} & $f^{a}$ & \\
\hline 1 & - & - & - & - & - & $(56)^{1}$ \\
\hline 2 & 720 & 1.72 & 616 & 2.01 & 0.134 & $\begin{aligned} 0.91 \times 56 & \rightarrow 57 \\
-0.38 \times 53 & \rightarrow 36\end{aligned}$ \\
\hline 3 & $(510 \mathrm{sh})$ & $(2.43)$ & 474 & 2.62 & 0.003 & $\begin{aligned} 0.96 \times 55 & \rightarrow 56 \\
+0.23 \times 55 & \rightarrow 57\end{aligned}$ \\
\hline 4 & & & 470 & 2.64 & 0.002 & $\begin{array}{r}0.96 \times 54 \rightarrow 56 \\
-0.23 \times 54 \rightarrow 57\end{array}$ \\
\hline 5 & 445 & 2.79 & 396 & 3.13 & 0.509 & $\begin{array}{r}0.87 \times 53 \rightarrow 56 \\
+0.25 \times 56 \rightarrow 57\end{array}$ \\
\hline
\end{tabular}

$a$ from the spectrum of ionized $\mathbf{3 b}$ shown in Figure $5 ;{ }^{b}$ MO 56 is the singly occupied HOMO of $\mathbf{9}^{*}$ which corresponds to the allylic NBMO of the azomethine ylide; MOs 53 and 57 are also allylic MOs, whereas the nearly degenerate MOs 53 and 54 are centered on one or the other of the two benzene rings. 
Figure 1. Transient absorption spectrum obtained after pulse radiolysis of a $0.1 \mathrm{mM}$ aqueous solution of 1 , saturated with $\mathrm{N}_{2} \mathrm{O}$ and ontaining $1 \mathrm{mM} \mathrm{Tl}_{2} \mathrm{SO}_{4}$ at $\mathrm{pH}$ 6.6. The insets shows the kinetics at 360 and $440 \mathrm{~nm}$

Figure 2. Top: Transient absorption spectrum obtained after pulse radiolysis of a $0.2 \mathrm{mM}$ aqueous solution of 1 containing $1 \mathrm{mM} \mathrm{K}_{2} \mathrm{~S}_{2} \mathrm{O}_{8}$ and $0.1 \mathrm{M}$ tert-butanol at $\mathrm{pH}$ 6.6. Inset shows the kinetics at $440 \mathrm{~nm}$; bottom: Transient absoprtion spectrum recorded after pulse radiolysis of $4 \mathrm{mM}$ of 1 in $n$-butyl chloride (filled squares) and after ${ }^{60} \mathrm{Co}-\gamma$-radiolysis in a Freon matrix at $77 \mathrm{~K}$. (solid line)

Figure 3. Transient absorption spectrum of $0.1 \mathrm{mM} 1$ observed on pulse radiolyis of an $\mathrm{N}_{2} \mathrm{O}$ saturated aqueous solution at $\mathrm{pH} 8$.

Figure 4: Transient absorption spectrum observed after pulse radiolysis of a $0.2 \mathrm{mM}$ aqueous solution of 2 containing $2 \mathrm{mM} \mathrm{K}_{2} \mathrm{~S}_{2} \mathrm{O}_{8}$ and $0.1 \mathrm{M}$ tert-butanol at $\mathrm{pH} 6$ (open squares), and on ${ }^{60} \mathrm{Co}-\gamma$-radiolysis in a Freon matrix at $77 \mathrm{~K}$ (solid line)

Figure 5: : Transient absoprtion spectra recorded after pulse radiolysis of $9 \mathrm{mM}$ of $\mathbf{3 b}$ (open squares) and $8 \mathrm{mM}$ of $\mathbf{3 a}$ (open squares) in $n$-butyl chloride and after ${ }^{60} \mathrm{Co}-\gamma$-radiolysis of the same two 2,3-diphenylaziridines in a Freon matrix at $77 \mathrm{~K}$. (solid lines)

Figure 6. Transient absorption spectra recorded after pulse radiolysis ofa $0.2 \mathrm{mM}$ of $\mathbf{4 a}$ containing $1 \mathrm{mM} \mathrm{K}_{2} \mathrm{~S}_{2} \mathrm{O}_{8}$ and $0.1 \mathrm{M}$ tert-butanol at $\mathrm{pH} 6$ (open circles), on pulse radiolysis of a $9 \mathrm{mM}$ solution of $\mathbf{4 a}$ in $n$-butyl chloride (open squares), and on ${ }^{60} \mathrm{Co}-\gamma$-radiolysis in a Freon matrix at $77 \mathrm{~K}$ (solid line)

Figure 7. Transient absorption spectra observed after pulse radiolysis of a $0.1 \mathrm{mM}$ aqueous solution of $\mathbf{4 b}$ containing $10 \mathrm{mM} \mathrm{NaN}_{3}$ at $\mathrm{pH} 8$ (open triangles), a $9 \mathrm{mM}$ solution of $\mathbf{4 b}$ in $n$ butyl chloride, and on ${ }^{60} \mathrm{Co}-\gamma$-of $\mathbf{4 b}$ a Freon matrix at $77 \mathrm{~K}$. 
Figure 8: Top: difference spectrum observed after $\gamma$-radiolysis of 1,2,3-triphenylaziridine 5 in Freon at $77 \mathrm{~K}$; center: difference spectrum for the subsequent photolysis at $>715 \mathrm{~nm}$; bottom: difference spectrum for the bleaching of the azomethine ylide radical cation at 475 $\mathrm{nm}$.

Figure 9: Structural changes on ionization of $\mathbf{1}$ and shapeof the singly occupied MO in the resulting radical cation.

Figure 10: Shape of the singly occupied MO of the radical cation obtained from 1-methyl-2phenylaziridine and structural changes on oxidation.

Figure 11: .Molecular orbitals of the 1-phenyl-azomethine ylide radical cation $\mathbf{8}^{+\bullet}$ that are involved in the electronic transitions listed in Table 1

Figure 12: Shape of the singly occupied MO of the radical cation obtained from 1-methyl-, 2,3-diphenylaziridine and structural changes on oxidation.

Figure 13: Shape of the singly occupied MO of the radical cation obtained from 1,2diphenylaziridine and structural changes on oxidation.

Figure 14: Thermochemistry of the ring opening reactions of different phenylaziridines from B3LYP/6-31G* calculations 
Graphical Abstract

\section{Radical Cations of Phenyl-Substituted Aziridines:}

\section{What are the Conditions for Ring-Opening?}

Carsten Gaebert $^{\text {a) }}$, Jochen Mattay*a), Marion Toubartz ${ }^{\text {b) }}$, Steen Steenken ${ }^{\text {b) }}$, Beat Müller ${ }^{\text {c) }}$, and Thomas Bally*c)

a) Organische Chemie I, Fakultät für Chemie, Universität Bielefeld, Postfach 100 131, D33501 Bielefeld, Germany. E-mail: mattay@uni-bielefeld.de.b) Max-Planck-Institut für Strahlenchemie, Stiftstr. 34-36, D-45470 Mülheim/Ruhr, Germany. c) University of Fribourg, Department of Chemistry, chemin du Musée 9, CH-1700 Fribourg, Switzerland. E-mail: thomas.bally@unifr.ch<smiles>[R]C1C([R])N1[R]</smiles>

$\mathrm{R}_{1}=\mathrm{H}, n-\mathrm{Bu}$, or $\mathrm{Ph}$

$\mathrm{R}_{2}, \mathrm{R}_{3}=\mathrm{H}$ or $\mathrm{Ph}$

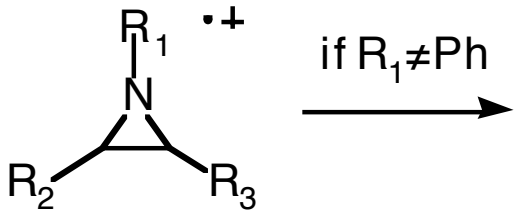

azomethine ylide radical cation 


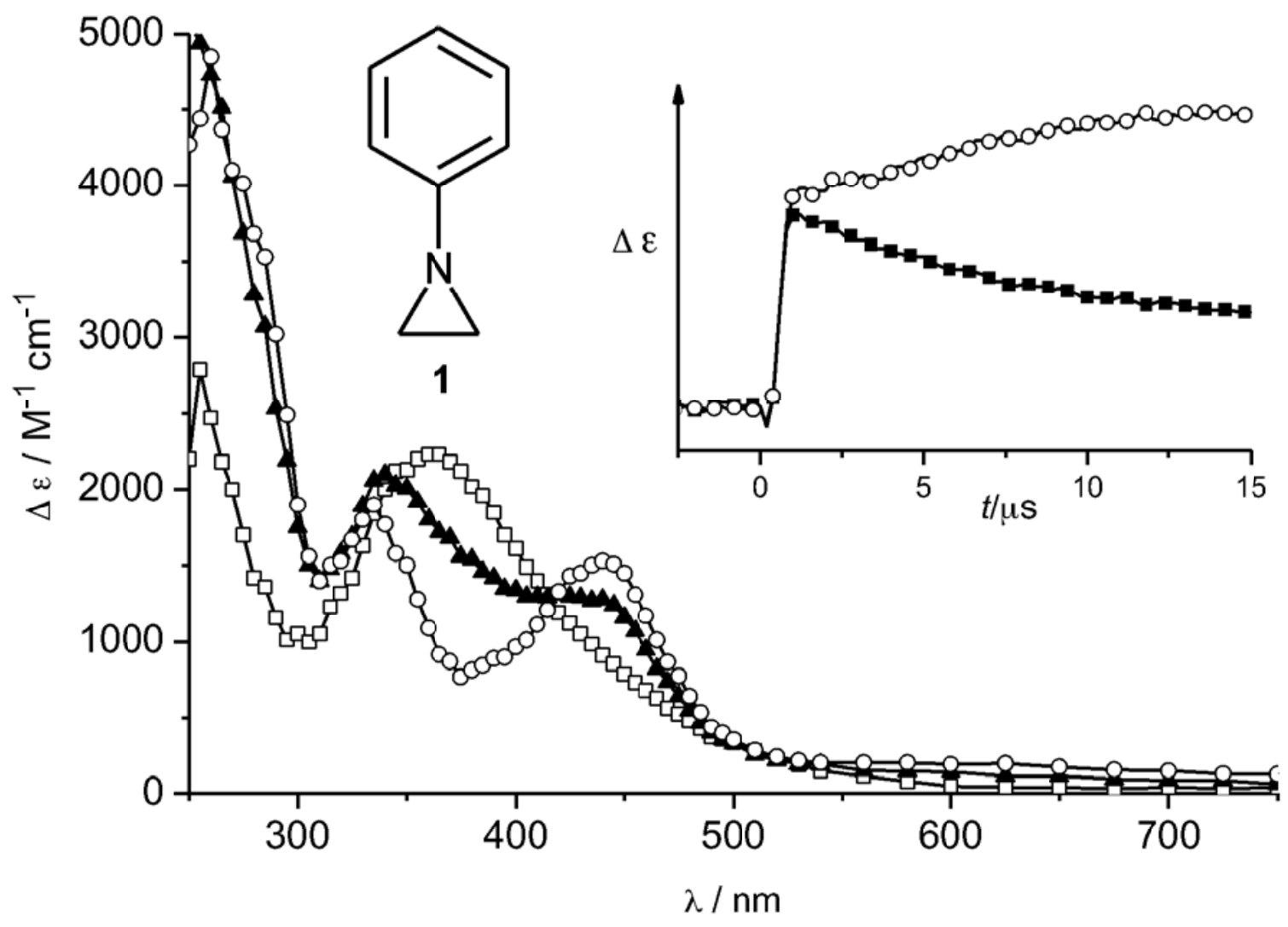

Figure 1 


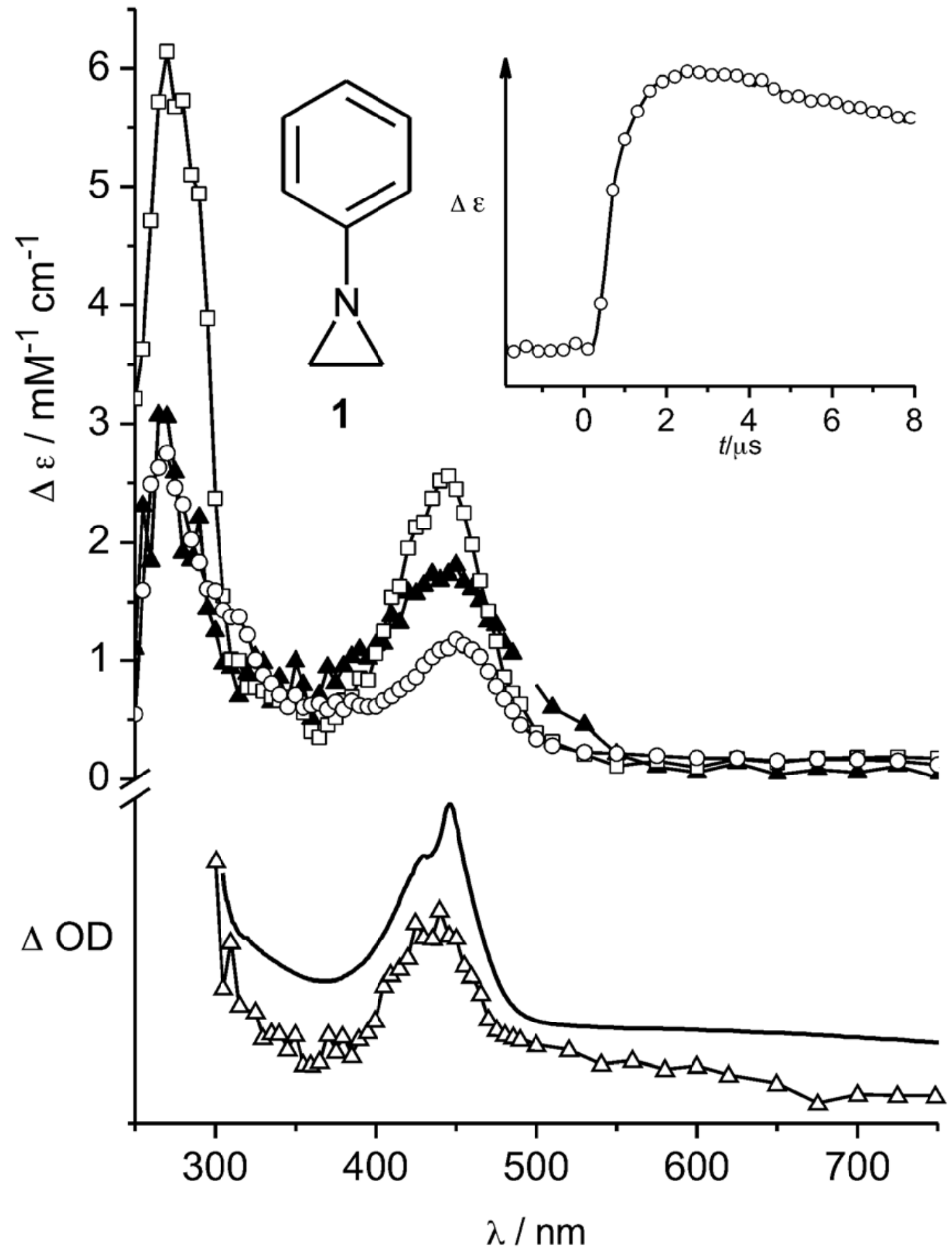

Figure 2 


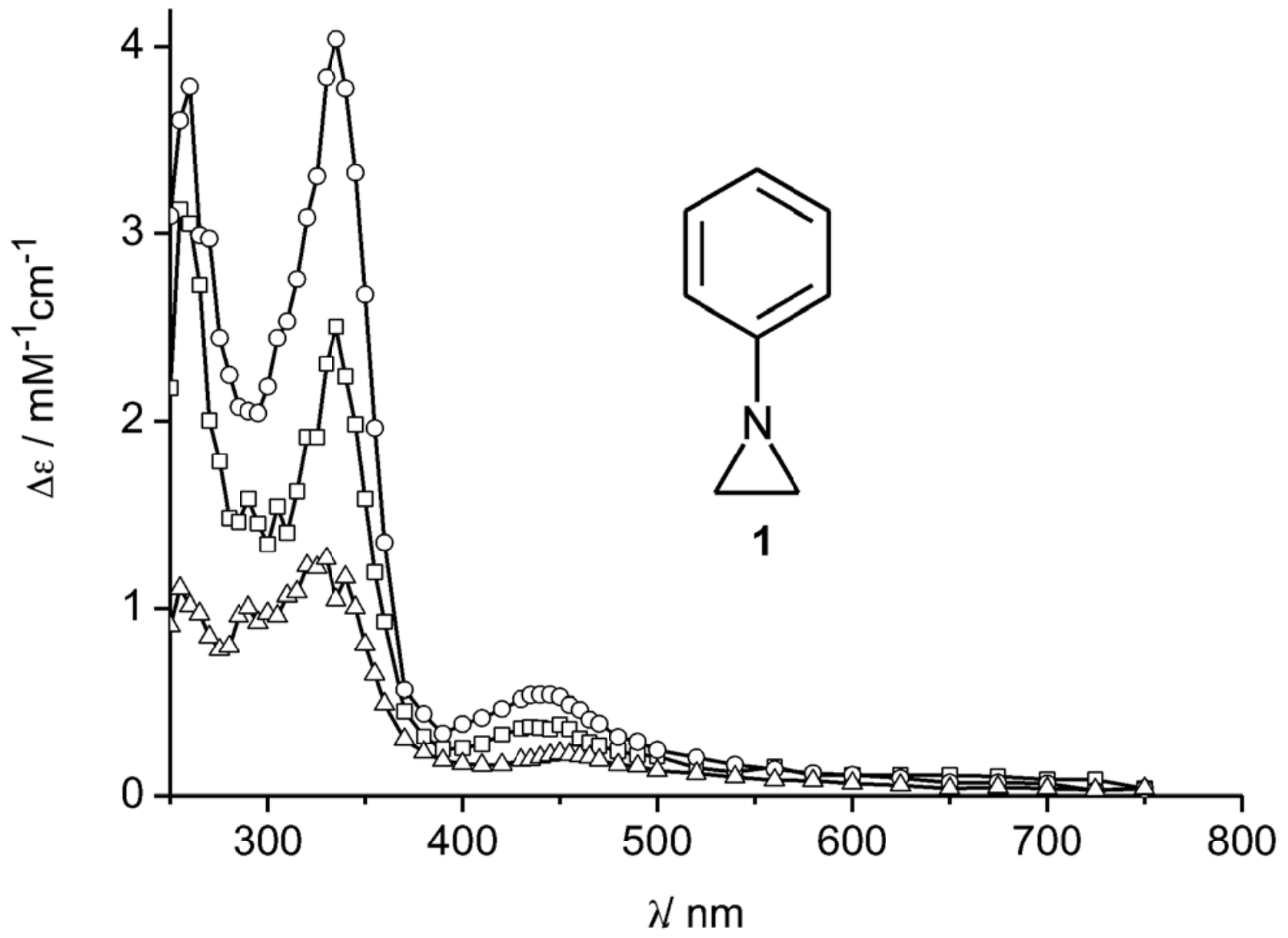

Figure 3 


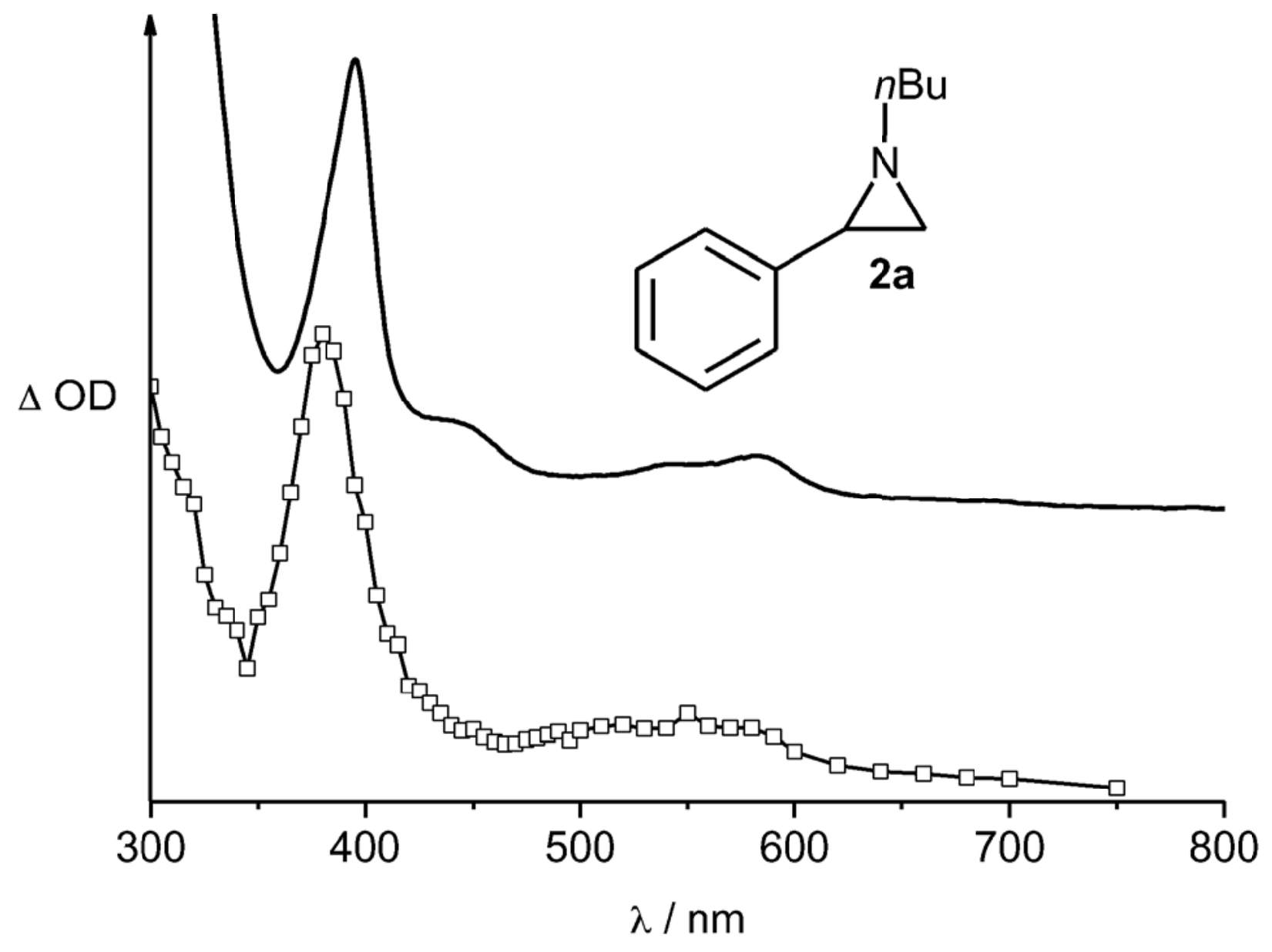

Figure 4 


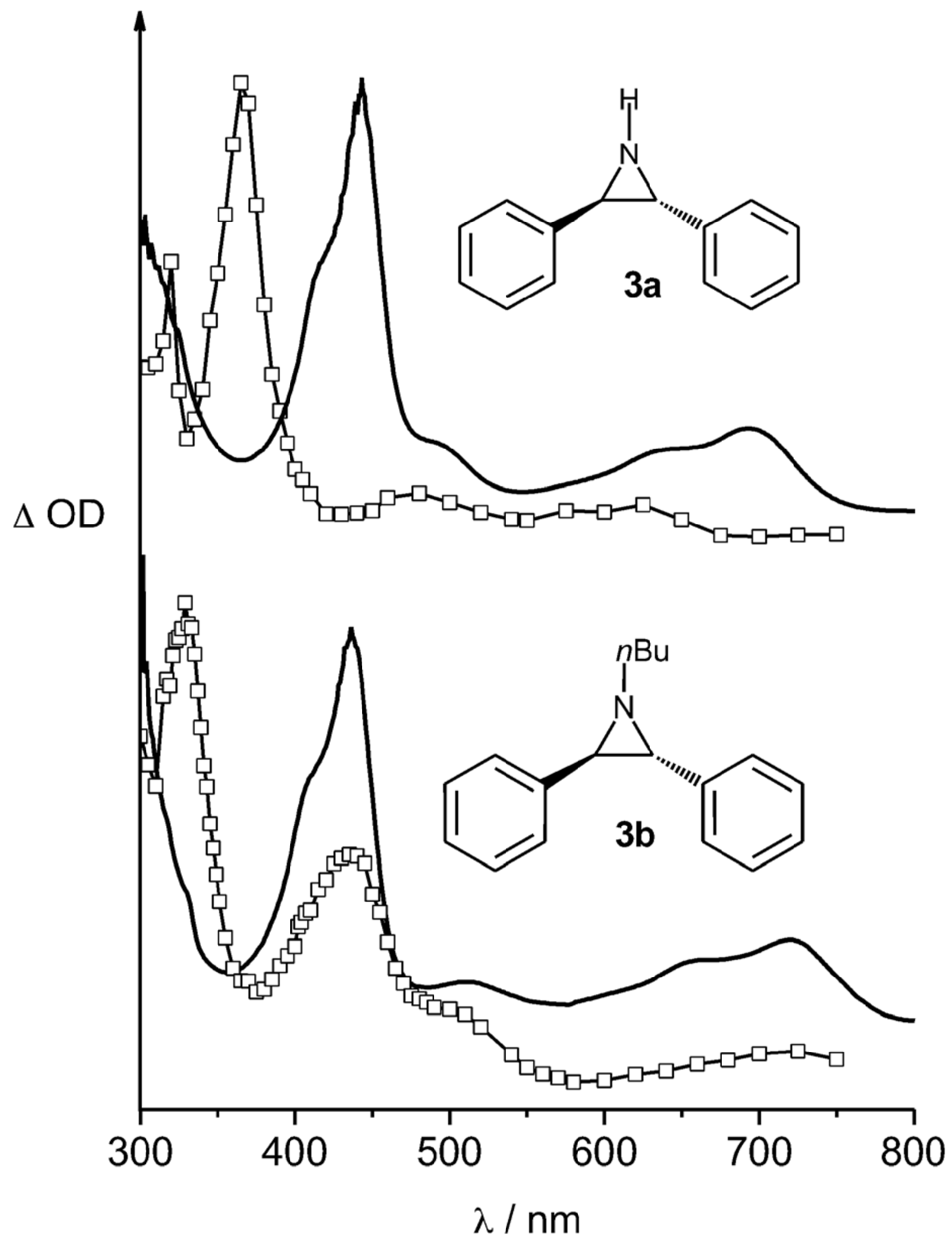

Figure 5 


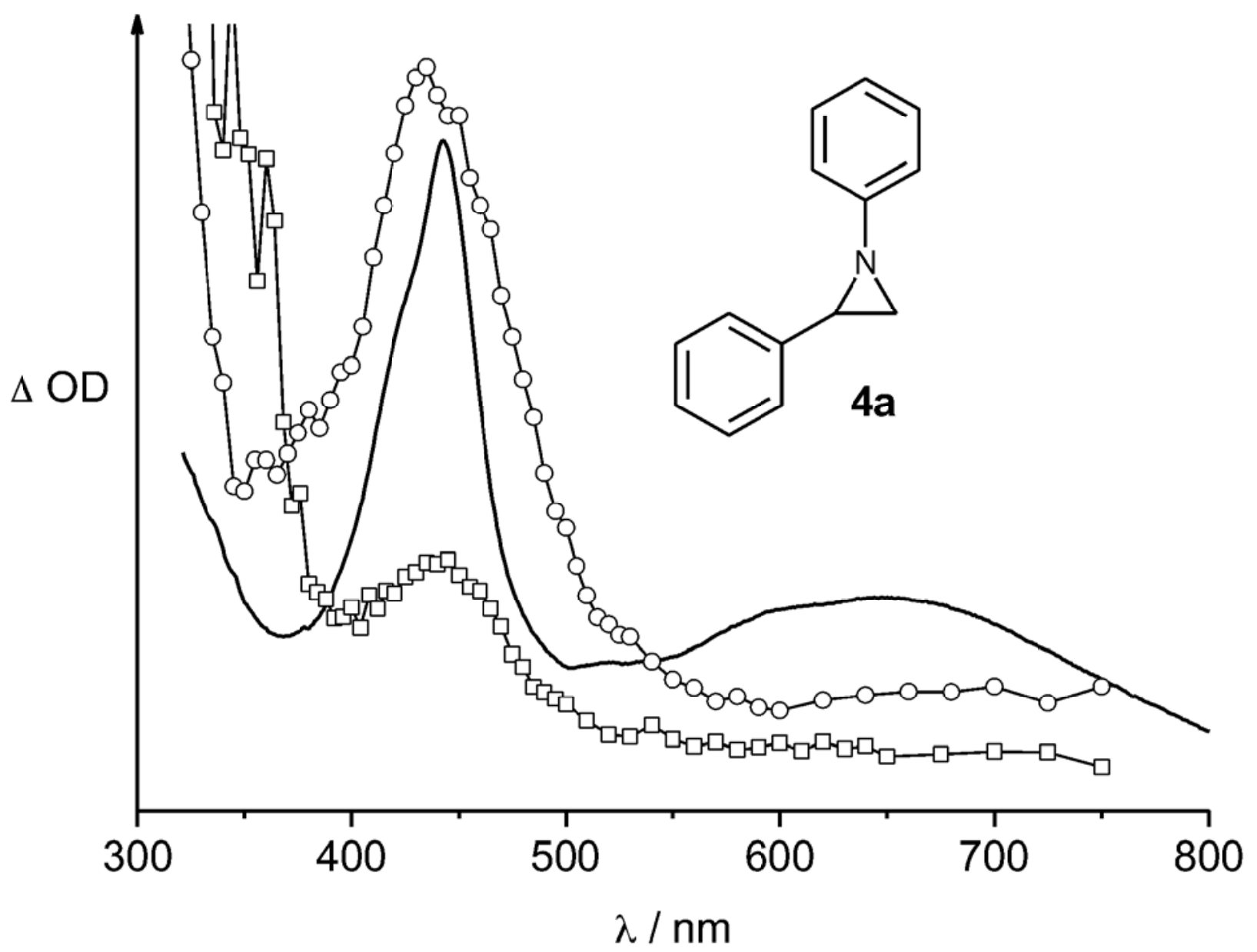

Figure 6 


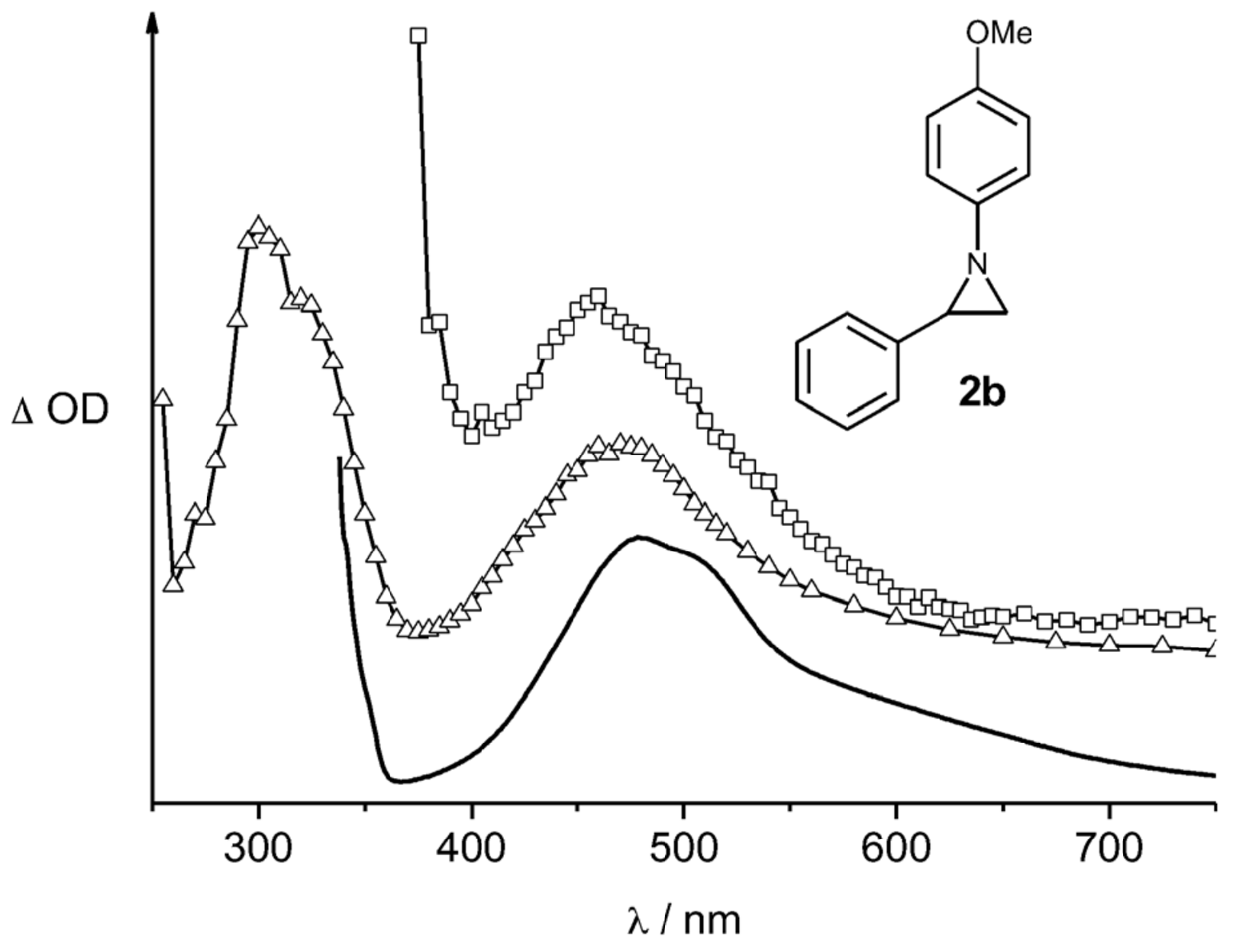

Figure 7 


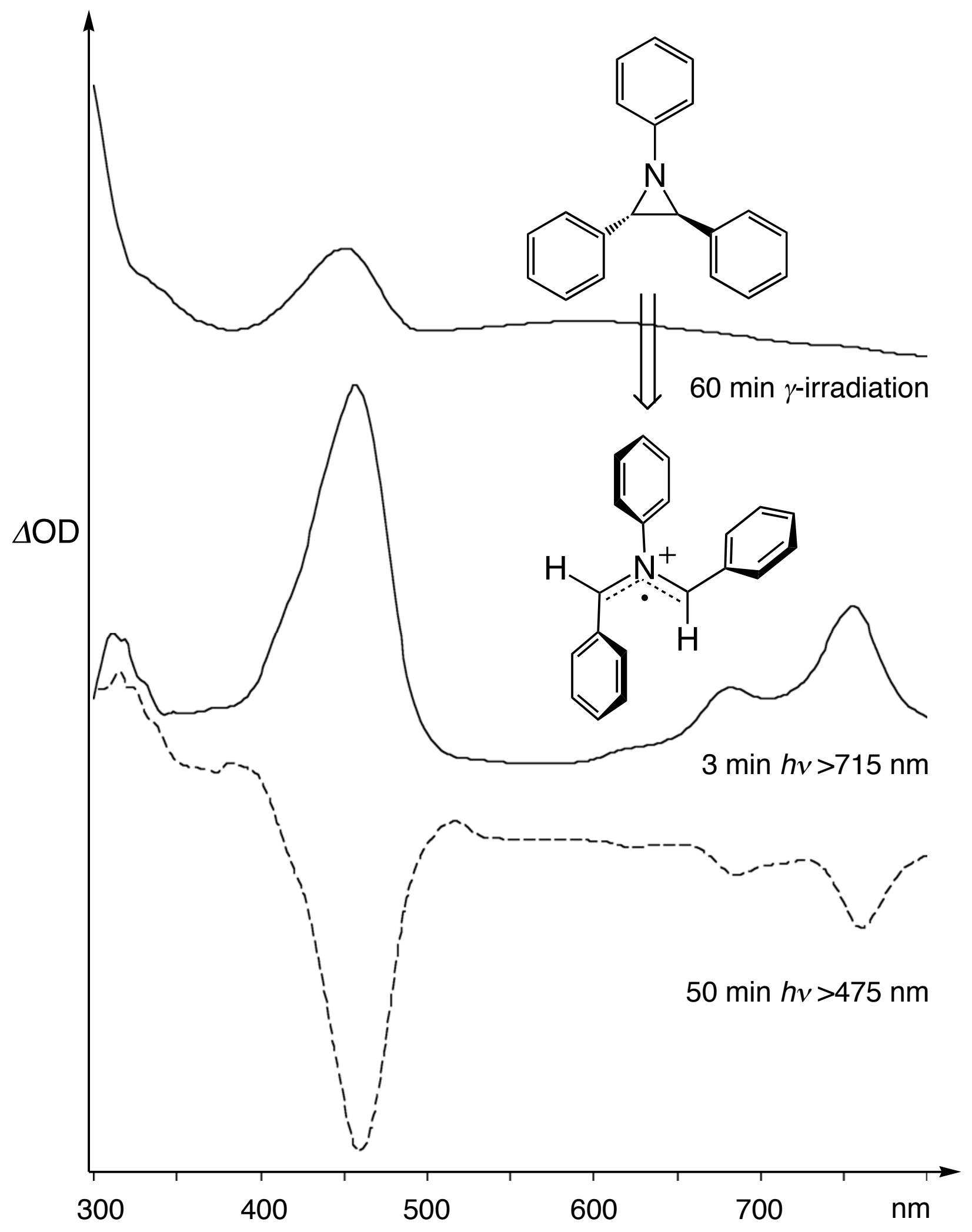

Figure 8 


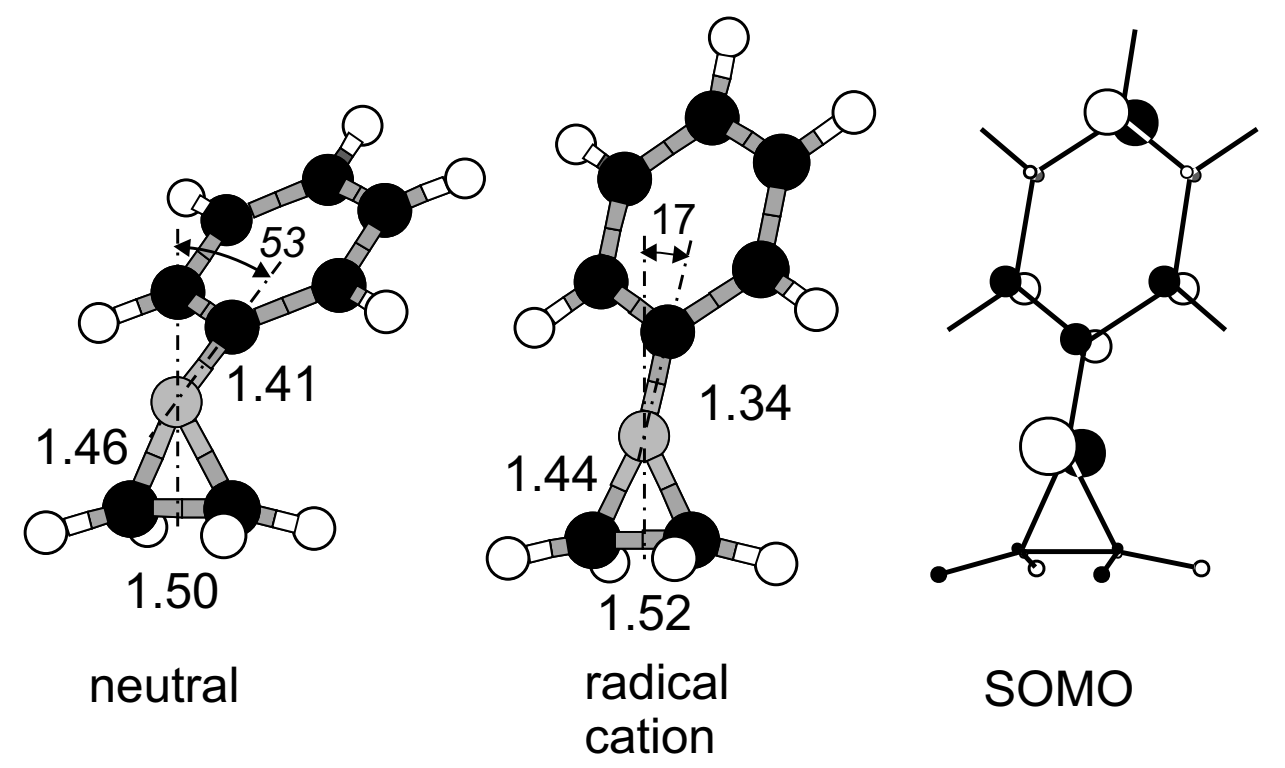

Figure 9

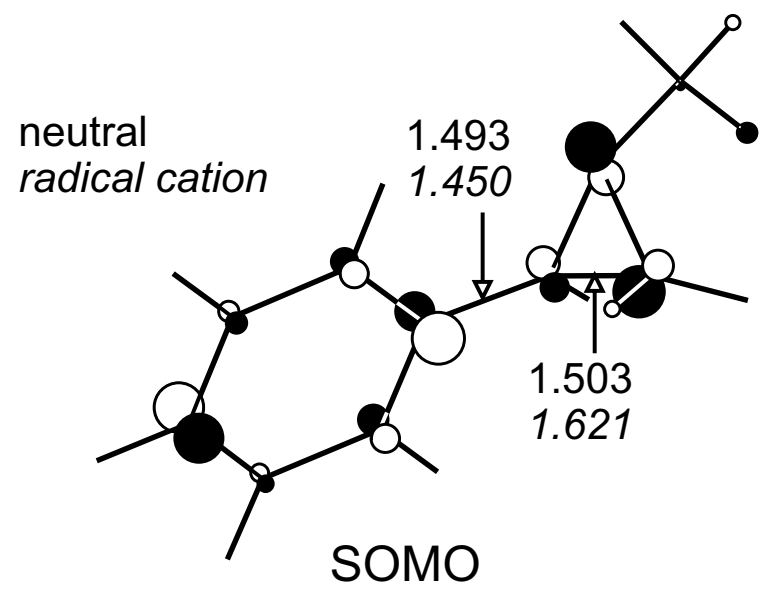

Figure 10 


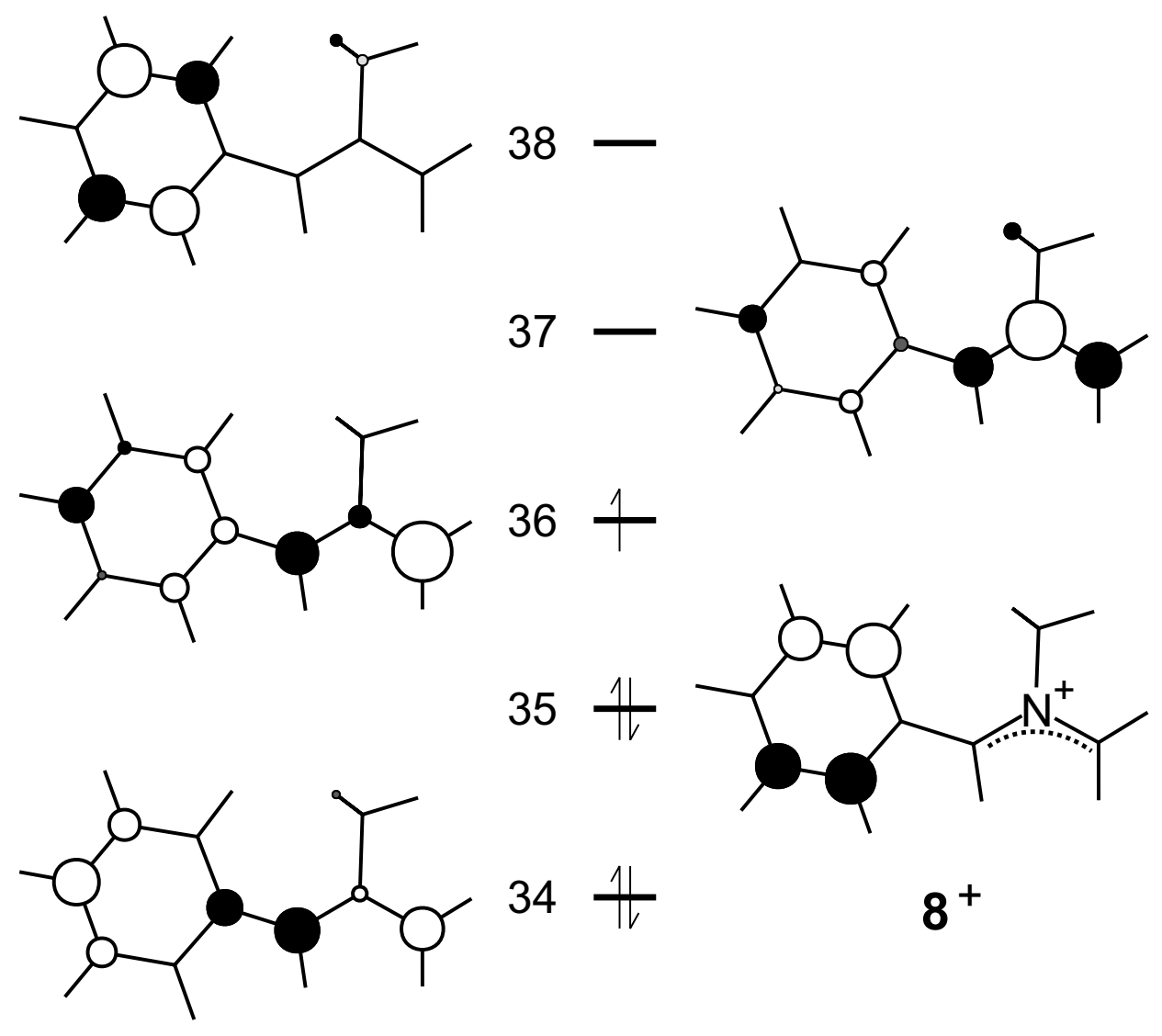

Figure 11 


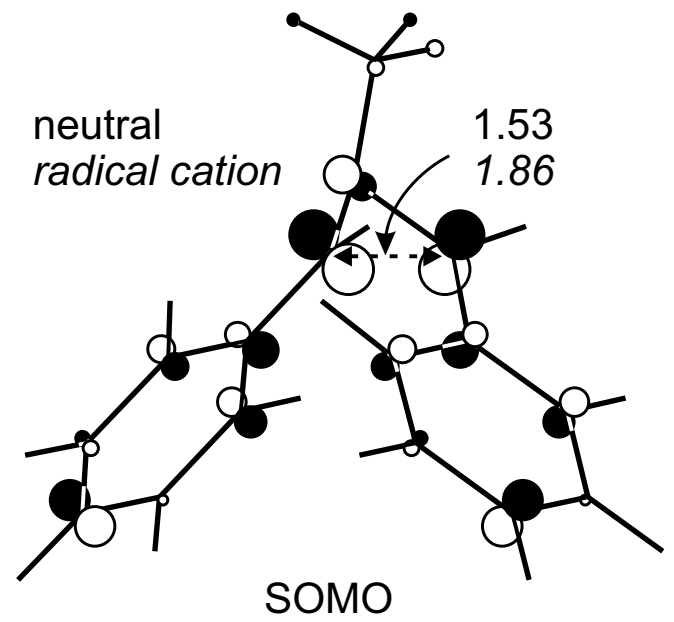

Figure 12

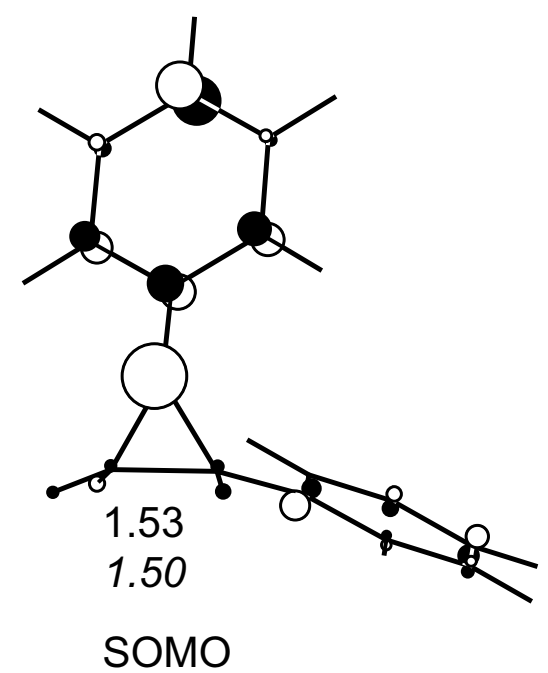

Figure 13 


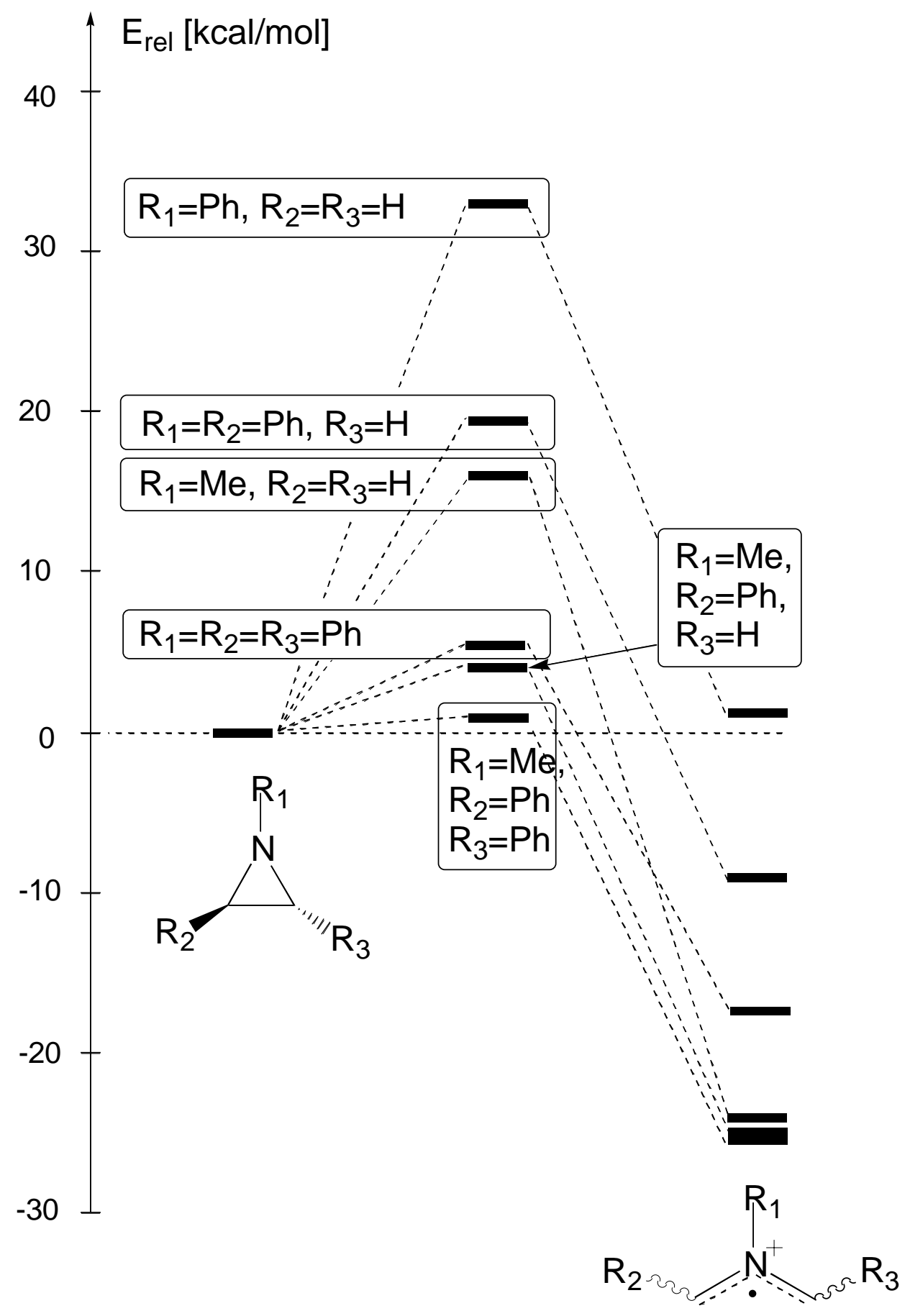

Fgiure 15 